\title{
A Measurement System for Characterizing the Detection Performance of Metal Detectors: Design and Operation
}

Nicholas G. Paulter, Jr. Donald R. Larson

Robert H. Palm, Jr.

U.S. DEPARTMENT OF COMMERCE Technology Administration

Electronic Instrumentation and Metrology Group Electricity Division

National Institute of Standards and Technology.

Gaithersburg, MD 20899

QC

100

.456

NO. 6530

\section{NLT}

National Institute of Standards and Technology Technology Administration U.S. Department of Commerce. 



\section{A Measurement System for Characterizing the Detection Performance of Metal Detectors: Design and Operation}

Nicholas G. Paulter, Jr. Donald $\boldsymbol{R}$. Larson Robert H. Palm, Jr.

U.S. DEPARTMENT OF COMMERCE Technology Administration Electronic Instrumentation and Metrology Group Electricity Division National Institute of Standards and Technology Gaithersburg, MD 20899

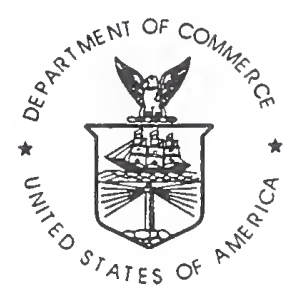

U.S. DEPARTMENT OF COMMERCE William M. Daley, Secretary TECHNOLOGY ADMINISTRATION Dr. Cheryl L. Shavers, Under Secretary of Commerce for Technology NATIONAL INSTITUTE OF STANDARDS AND TECHNOLOGY

Raymond G. Kammer, Director 



\title{
A MEASUREMENT SYSTEM FOR CHARACTERIZING \\ THE DETECTION PERFORMANCE \\ OF METAL DETECTORS: DESIGN AND OPERATION
}

\author{
Nicholas G. Paulter, Jr. \\ Donald R. Larson \\ Robert H. Palm, Jr.
}

\begin{abstract}
:
A measurement system for evaluating the performance of hand-held $(\mathrm{HH})$ and walk-through (WT) metal detectors is described. These detectors produce time-varying magnetic fields that interact with objects comprised of electrically conductive and/or magnetizable materials and this interaction allows detection of the object. Detection performance parameters considered are the magnitude of the magnetic field inside the portal region of a WT metal detector and around the $\mathrm{HH}$ detector, the ability to detect the presence of small metal objects, the speeds over which small metal objects can be detected, detection repeatability, and discrimination between target objects and innocuous items. Standardized metal objects are used for testing detector sensitivity, and these objects have been defined as threat items by local, state, and federal law enforcement and corrections agencies.
\end{abstract}

\section{Acknowledgments:}

The authors are grateful to the National Institute of Justice, the Federal Bureau of Prisons, and the Office of Law Enforcement Standards of the National Institute of Standards and Technology (NIST) for support of this work. We also thank K. Rice and B. Waltrip of NIST for technical comments on this document and B. Bell of NIST for administrative support. 


\section{TABLE OF CONTENTS}

Page

TABLE OF CONTENTS $\ldots \ldots \ldots \ldots \ldots \ldots \ldots \ldots \ldots \ldots \ldots \ldots \ldots \ldots \ldots \ldots$ ii

1. INTRODUCTION . . . . . . . . . . . . . . . . . . . . . . . . . .

2. MEASUREMENT SYSTEM ........................... 2

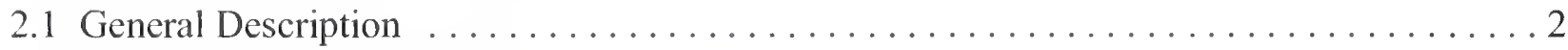

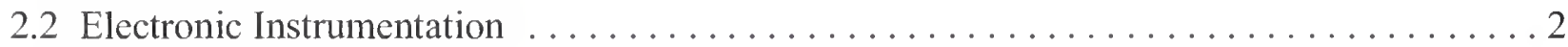

2.3 Mechanical System . . . . . . . . . . . . . . . . . . . . . . . . .

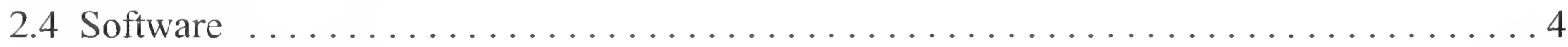

3. TEST METHODS . . . . . . . . . . . . . . . . . . . . . . . . . 12

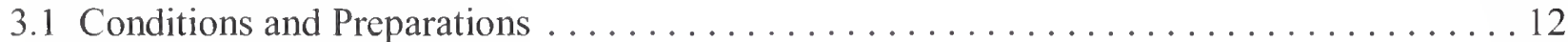

3.2 Test Objects . . . . . . . . . . . . . . . . . . . . . . . . . 13

3.3 Initial Test Procedures, General . . . . . . . . . . . . . . . . . . . . . 13

3.4 Detection Sensitivity . . . . . . . . . . . . . . . . . . . . . 14

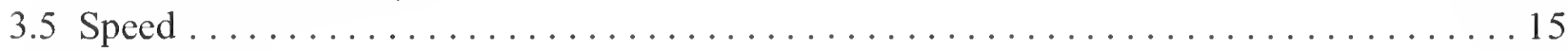

3.6 Repeatability . . . . . . . . . . . . . . . . . . . . . . . 16

3.7 Discrimination . . . . . . . . . . . . . . . . . . . . . . . . 16

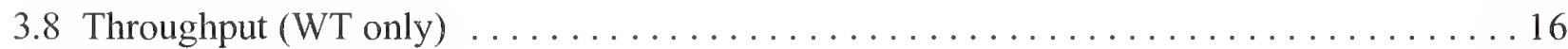

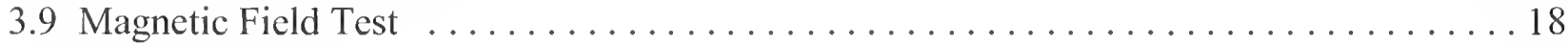

4. References ........................................ . 19

5.1 Appendix 1, Parts list for robotic positioner and hand-held detector holder . . . . . . . 20

5.2 Appendix 2, Robot positioner drawings . . . . . . . . . . . . . . . . . . 22

5.3 Appendix 3, Hand-held metal detector positioner drawings . . . . . . . . . . . . . 37

5.4 Appendix 4, Detector-holder-to-robot spacer drawing $\ldots \ldots \ldots \ldots \ldots \ldots \ldots \ldots \ldots$ 


\section{INTRODUCTION}

Hand-held (HH) and walk-through (WT) metal detectors are the primary tools in security screening applications. For security applications, these detectors are used to find metal weapons and metal contraband items hidden on an individual. Although these detectors are used primarily for finding metal objects, they can also sense non-metal electrically conductive and/or magnetizable objects.

HH and WT metal detectors function by producing a time-varying magnetic field and then sensing the interaction of this magnetic field with any nearby objects. The interaction results in the induction of an eddy current in the object or magnetization of the object. Typically, the eddy current generation is the dominant mode of interaction and yields the largest detection response.

Measuring certain characteristics of the HH and WT metal detectors is important for performance reasons. The primary performance issue is to ensure that the HH and WT metal detectors function properly as a security screening tool. These detectors must sense repeatedly, and often times in rapid succession, the presence of appropriately sized metal objects.

In this document, we describe the measurement system and methods that have been developed for characterizing the performance of HH and WT metal detectors. In Section 2, the measurement system is described, including electronic, mechanical, and software components. In Section 3, the performance test methods are described. These methods include detection sensitivity, speed, repeatability, discrimination, and throughput (WT only). 


\section{MEASUREMENT SYSTEM}

\subsection{Gemeral Description}

The measurement system consists of electronic, mechanical, and software components (see fig.1). The electronic components include a computer for controlling all the instruments and acquiring, analyzing, and displaying the data; a three-axis magnetic field sensor for measuring the magnetic field intensity; a digitizing oscilloscope for acquiring the magnetic field intensity temporal profiles and the average field intensity. The mechanical component is a cartesian robot, including the motor power supplies required for motion control. The software is used for instrument control and data acquisition, analysis, and display.

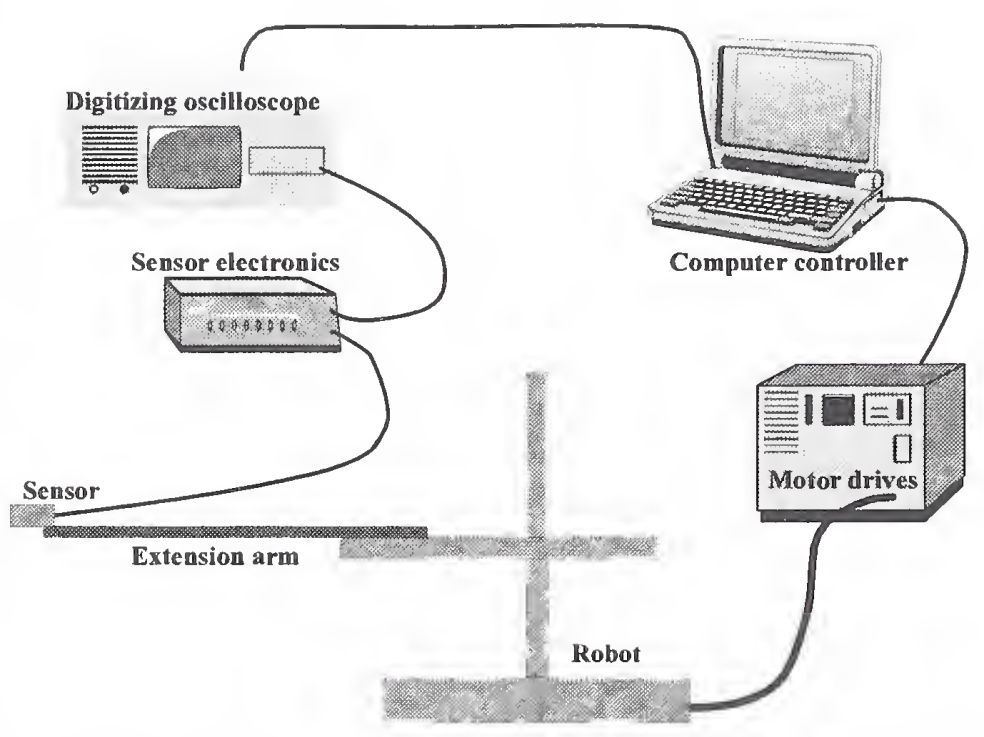

Figure 1. Measurement system showing hardware components.

\subsection{Electronic Instruments}

The electronic instruments include a digitizing oscilloscope, computer controller, and magnetic field sensors. The oscilloscope is used to acquire the waveform of the time-varying magnetic fields produced by the HH and WT metal detectors. These detectors may produce continuous wave or pulse fields but because the bandwidth of the magnetic fields is less than $10 \mathrm{MHz}$, almost any low bandwidth digitizing oscilloscope can be used. The digitizing oscilloscope should have the following minimum specifications:

1. interface for remote microprocessor control including data retrieval

2. frequency bandwidth $>$ ten times the frequency bandwidth of the field under test

3. internal waveform storage

4. voltage axis:

Gain: variable

Resolution: $\geq 8$ bit

Maximum input: $1 \mathrm{~V}$ peak

Uncertainty: $<2 \%$ of full scale 
5. time (horizontal) axis:

Uncertainty: $<1 \%$ of full scale

6. firmware for calculating peak-to-peak amplitude and average power of a waveform

The field sensors were not "off-the-shelf" and had to be custom designed to provide the required size, bandwidth, and dynamic range. The parameters for the field sensors are:

1. three-axis simultaneous sensing/output

2. size: $\leq 3.81 \mathrm{~cm} \mathrm{x} 3.81 \mathrm{~cm} \times 3.81 \mathrm{~cm}$

3. frequency (f) bandwidth, $-3 \mathrm{~dB}$ :

low frequency detector: $50 \mathrm{~Hz} \leq \mathrm{f} \leq 30 \mathrm{kHz}$

high frequency detector: $3 \mathrm{kHz} \leq \mathrm{f} \leq 3 \mathrm{MHz}$

4. output impedance: $\geq 1 \mathrm{M} \Omega$

5. electrical lead length between sensor and power supply/display $\geq 2 \mathrm{~m}$

6. real-time output for waveform display, and

7. dynamic range: $10 \mu \mathrm{G}$ to $1 \mathrm{G}$.

The low frequency range is used for the WT metal detectors and the high frequency range for the $\mathrm{HH}$ metal detectors.

The computer controller is a PC-based system and must contain an IEEE488 interface for instrument control and data acquisition and an RS232 port for motion control. The control and data acquisition functions were written using a graphical programming language.

\subsection{Mechanical System}

The mechanical system consists of a three-axis (cartesian) robot (see fig. 2) and the necessary motor controllers for positioning test objects and the magnetic field sensor with respect to the detector. The axes of the robot each have different requirements. The $\mathrm{x}$-axis is the lower unit and is a gantry system consisting of one linear actuator and two rail guides. The $\mathrm{z}$-axis system is mounted on top of the $\mathrm{x}$-axis gantry and consists of one linear actuator and a linear guide. The $y$-axis subsytem is mounted to the $\mathrm{z}$ axis subsystem and provides the

Figure 2. Drawing of robot. 
and provides the high-speed motion required for performing speed tests.

The specifications for the mechanical system are:

1. $\mathrm{x}$-axis (guides, $2 \mathrm{ea}$, and actuator), travel: $\geq 1 \mathrm{~m}$

2. $\mathrm{z}$-axis (guide, $1 \mathrm{ea}$, and actuator), travel: $\geq 2.1 \mathrm{~m}$

3. $y$-axis (actuator), travel: $\geq 1 \mathrm{~m}$; speed: $>2 \mathrm{~m} / \mathrm{s}$

4. limit switches for each axis, and

5. home switch for each axis.

Each axis is moved sequentially because of the possibility of exceeding the amperage rating of most circuit breakers, namely $10 \mathrm{~A}$. The $\mathrm{x}$-axis and z-axis displacement speeds have been adjusted to provide the best compromise between smooth and rapid travel. The $y$-axis displacement speed is adjustable. The $\mathrm{x}$-axis actuator is a ball screw drive. The $\mathrm{y}$-axis and $\mathrm{z}$-axis drives are belt drives because of the requirement for speed and/or long travel.

Assembly drawings of the robot controller are provided in the Appendix. Also provided in the Appendix are mechanical drawings of the NIST-designed components that are used in the robot.

\subsubsection{Cautions Regarding the Mechanical System}

Each actuator system (or axis positioner) must be tuned to operate under the desired mechanical load, range of motion, and speed according to the manufacturer of the actuator. Brakes should be used on the vertical (z-axis) positioner to prevent the $y$-axis subassembly from falling should a power or other failure occur. The power and control cables should be positioned so as not to bind or become damaged when any of the actuators are in motion.

There is a hardware fault that will cause an actuator to become non-responsive. This typically happens when the stage (or mounting platform) of an actuator reaches either end of the actuator (or an obstacle) and the motor does not automatically stop. When this occurs, the motor controller must be turned off and each stage re-positioned closest to their respective home positions. The home positions are the ends of travel closest to the motor. The motor control unit can then be turned back on and the testing continued.

\subsection{Software}

The software to control the robot positioner and acquire data is written in a graphical programming language, LabVIEWTM. 'Each LabVIEW'T program is called a "virtual instrument" or "VI" because it provides an instrument-like control screen or "front panel." The program is written such that one

\footnotetext{
${ }^{\mathrm{I}}$ No approval or endorsement of any commercial product by the National Institute of Standards and Technology is intended or implied. Certain commercial equipment, instruments, or materials are identified in this report in order to facilitate understanding. Such identification does not imply recommendation or endorsement by the National Institute of Standards and Technology, nor does it imply that the materials or equipment identified are necessarily the best available for the purpose.
} 
main VI is used to call subordinate VIs (subVIs). The subVIs execute the individual performance tests described herein. Each subVI requires specific and unique inputs for a given test. Furthermore, each subVI displays data appropriate for a given test, as will be seen in the following sections. The front panel for the main VI is shown in fig. 3. As can be seen in this figure, there are two selectable tests for the $\mathrm{HH}$ detector and three for the WT detector. The speed, repeatability, and discrimination tests are very similar and, therefore, use the same subVIs. However, not all inputs are necessary for each test.

Each subVI typically has the following general control buttons: "PAUSE," "ABORT," "EXIT," and "INITIALIZE." The "PAUSE" and "ABORT" buttons are used to temporarily stop or terminate program execution. The "PAUSE" button will cause the program to suspend execution of the program after the last command sent to the motor controller has been completed. Pushing the "PAUSE" button again causes the program to finish execution. Pressing the "ABORT" button will turn the $\mathrm{x}$ - and $\mathrm{y}$-axes motors off and then terminate program execution. The white arrow, visible in the upper left corner of the front panel, must be pressed to re-start the VI. The "EXIT" button is used to stop a test; the stages will return to the home position (namely, as near as possible to their

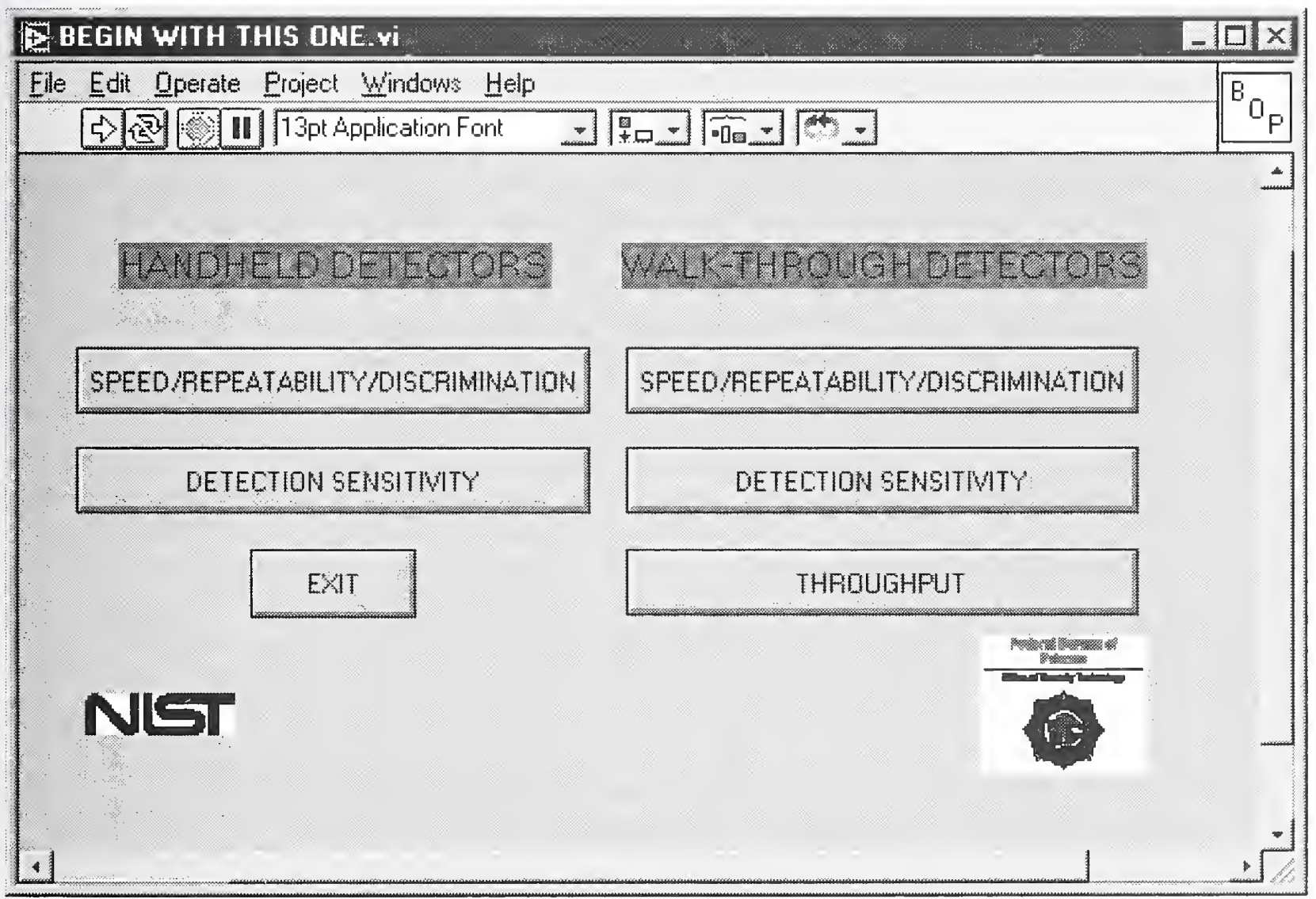

Figure 3. Front panel for main VI. 


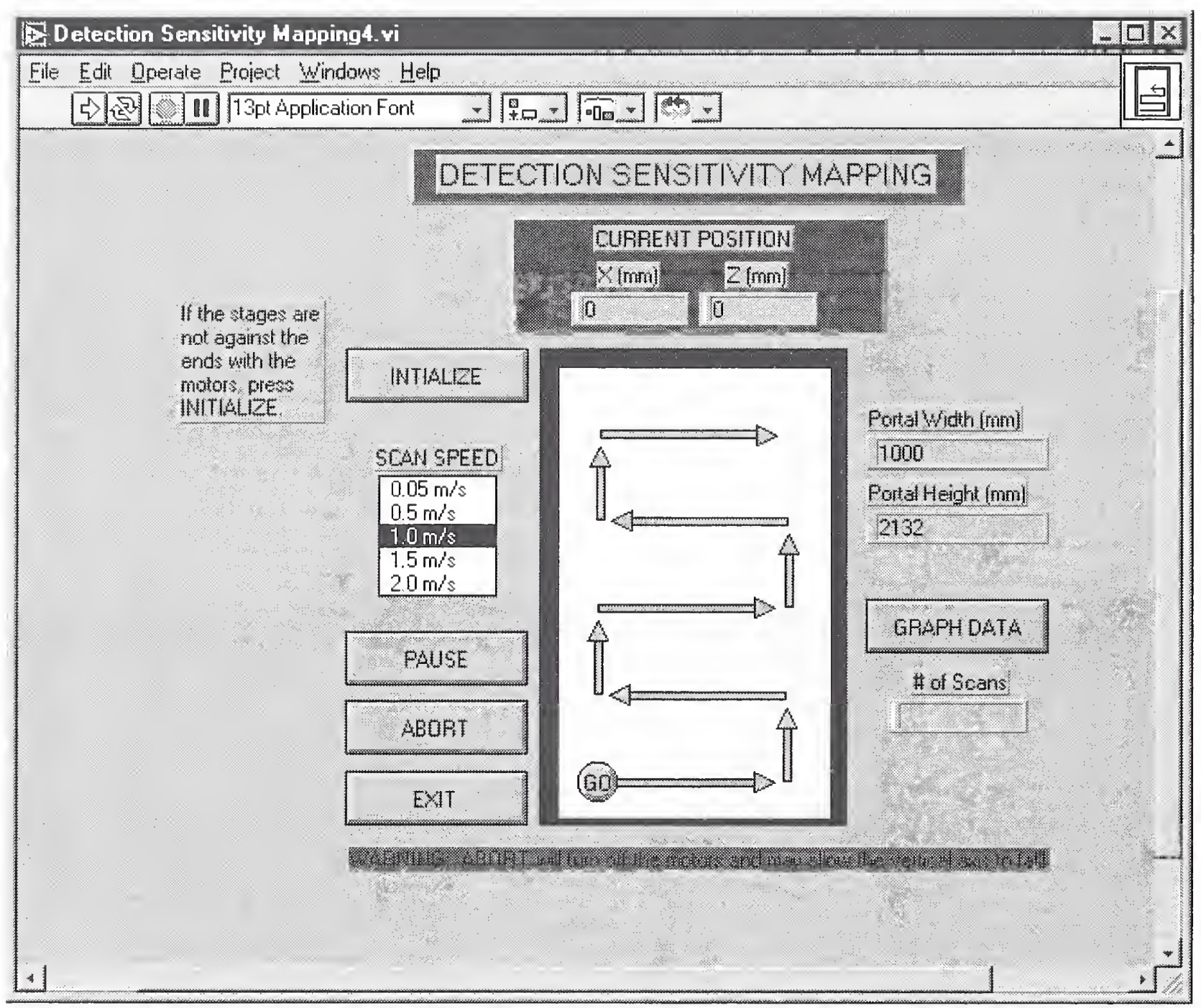

Figure 4. Front panel of the subVI used to perform the detection sensitivity mapping test on the WTMD.

respective motors) and then program execution terminates. The "INITIALIZE" button is used to locate the $\mathrm{x}$-axis (horizontal), $\mathrm{y}$-axis (in/out), and z-axis (vertical) home (or zero) positions of the robot positioner. The "INITIALIZE" button should be used prior to the start of any testing.

If the platform of one of the three axes is pushed too hard against an object (such as a foreign object in the path of the robot) or its stops, the corresponding motor will stop and the corresponding axis will be free to move. When this fault occurs, to re-start the program, LabVIEWTM must be closed, the motor controller and drives turned off and then turned back on, and the main VI re-loaded. 


\subsubsection{Detection Sensitivity}

The front panel display for the detection sensitivity mapping VI for the WT metal detector (WTMD) is shown in fig. 4. The diagram of the portal in the center of the front panel shows the path of the mapping process. The input requirements for program execution are portal width, portal height, and the $y$-axis scan speed. The portal width and height units are millimeters. The scan speed is switch selectable; however, the NIJ standard uses a nominal speed of $1 \mathrm{~m} / \mathrm{s}$ for this performance test. The current position $\mathrm{x}-\mathrm{z}$ location of the $\mathrm{y}$-axis scan is displayed above the portal. The $\mathrm{x}$-axis dimension is parallel to the portal width and the z-axis dimension is parallel to the portal height.

The "GO" button at the bottom left of the path must be pressed to start the program. Each y-axis scan produces a value that represents the maximum signal output from the detector for that scan. These maximum values are then inserted into a table to generate the detection sensitivity map. Each test

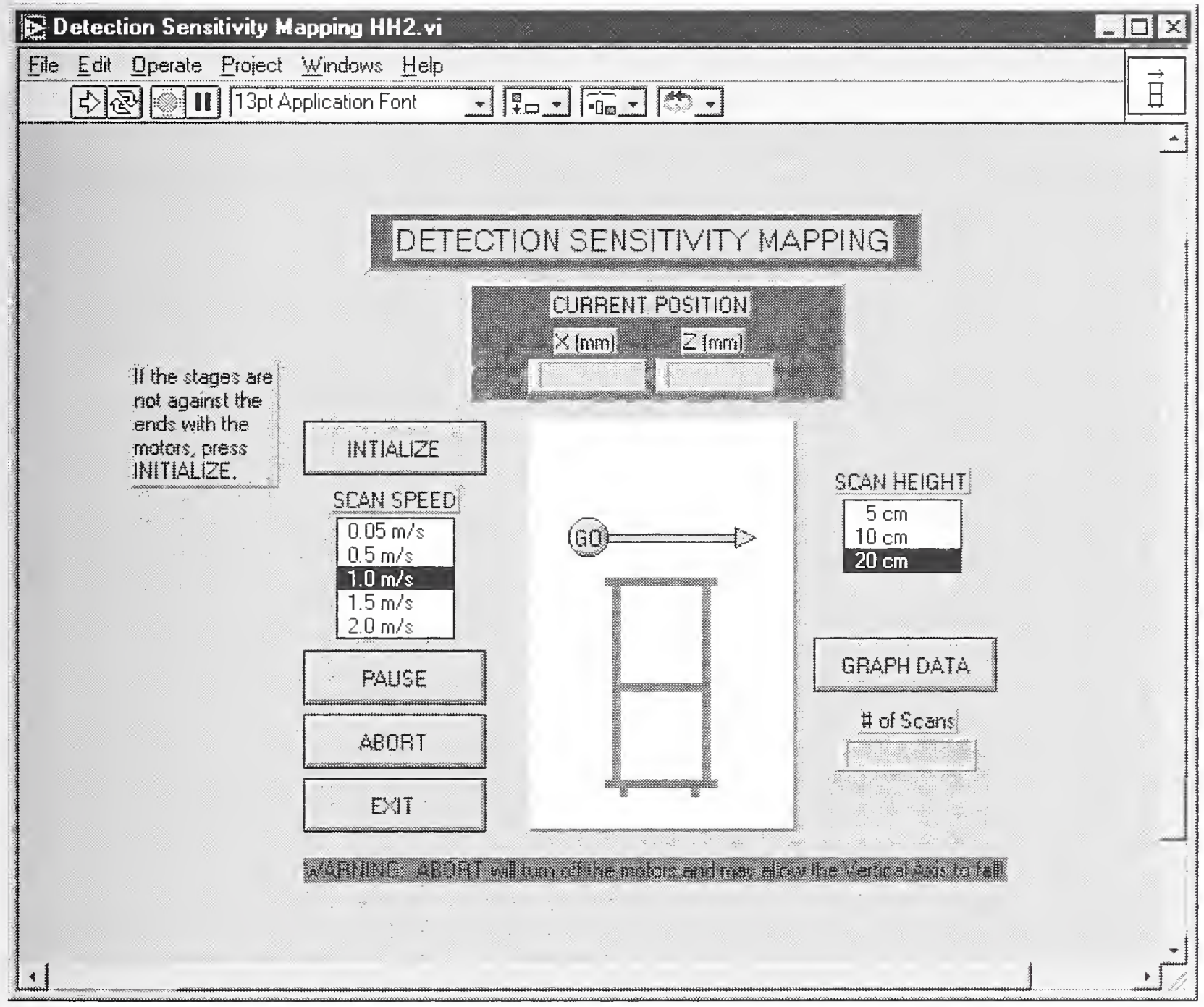

Figure 5. Front panel of the subVI used to perform the detection sensitivity mapping test on the HHMD. 
object and its allowed orientations will produce a unique detection sensitivity map. The "GRAPH DATA" button allows users to display the sensitivity map.

The front panel display for the detection sensitivity mapping subVI for the $\mathrm{HH}$ metal detector (HHMD) is shown in fig. 5. Each y-axis scan yields a series of values (a vector) that represents the response of the detector to the test object as the test object is moved past the detector. These vectors are then added to a table to yield the detection sensitivity map. Each test object and its allowed orientations for each measurement plane (see secs. 3.2 and 3.4.2.2) will produce a unique detection sensitivity map.

\subsubsection{Speed}

The front panel display for the speed test subVI for the WTMD is shown in fig. 6. The diagram of the portal and cartoon of a human in the center of the front panel allows selection of the $\mathrm{x}$-axis and $z$-axis positions for the test. The input requirements for program execution are the $y$-axis scan speed

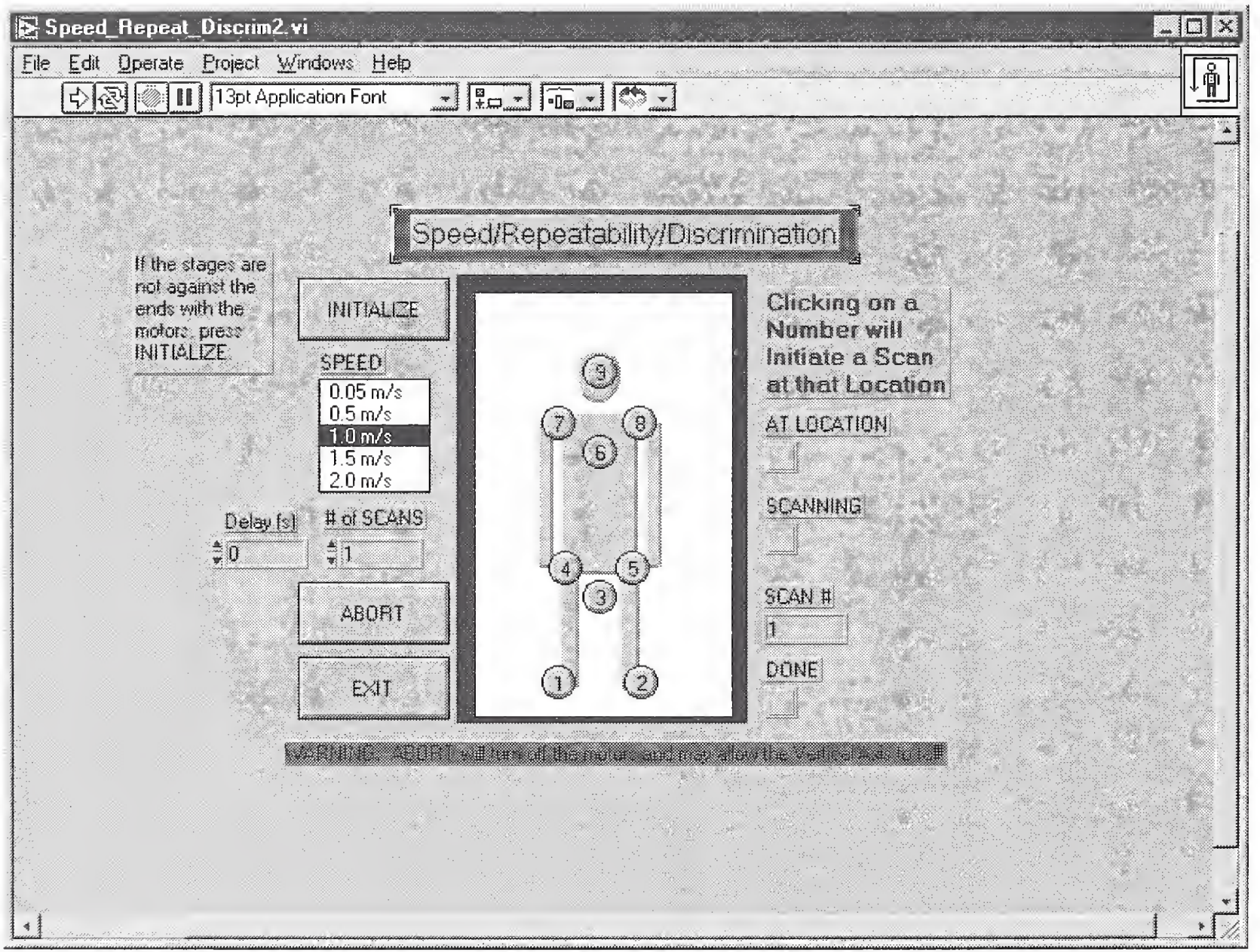

Figure 6. Front panel of the subVI used to perform speed, repeatability, and discrimination tests on the WTMD. 


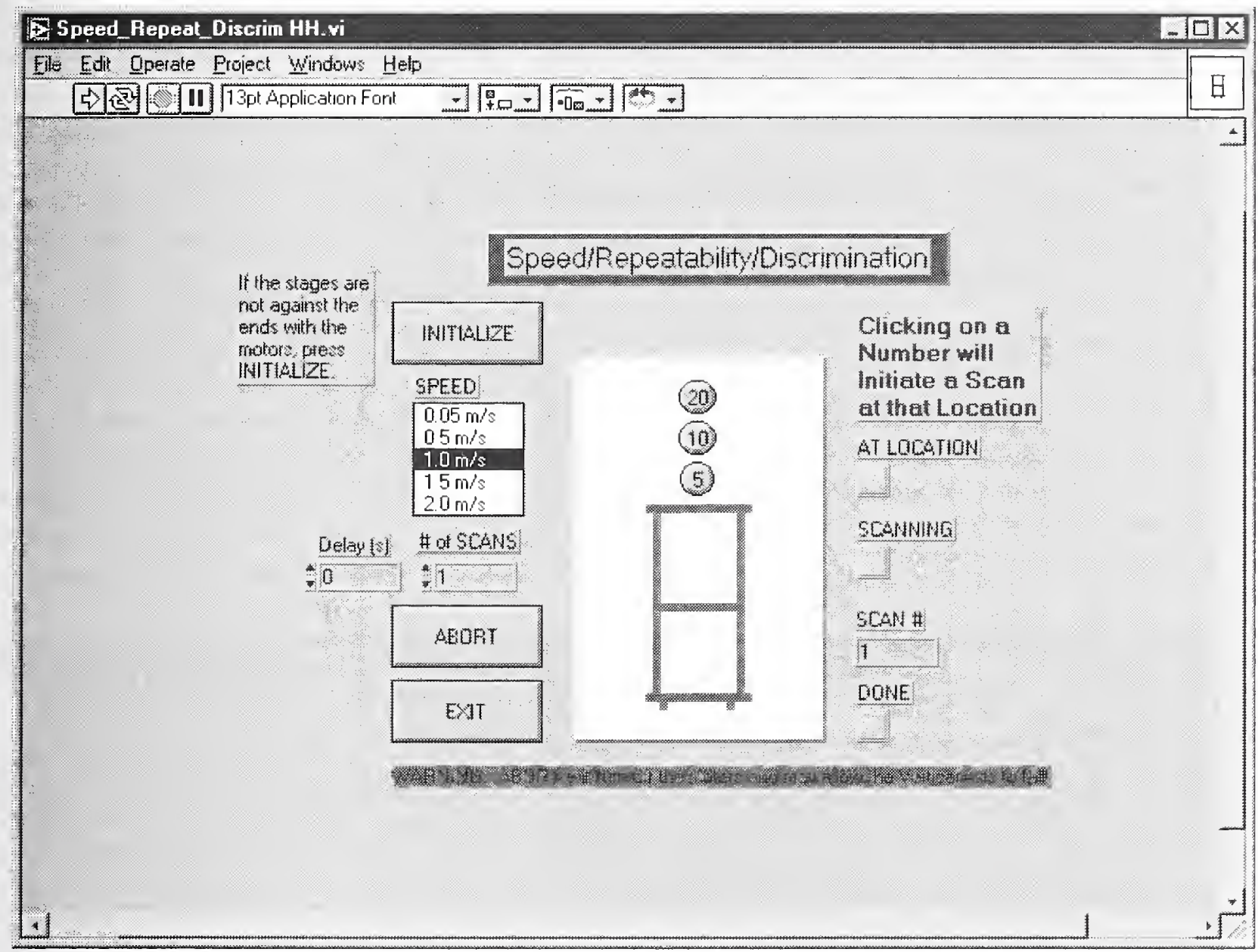

Figure 7. Front panel of the subVI used to perform speed, repeatability, and discrimination tests on the HHMD.

and the location in the $\mathrm{x}-\mathrm{z}$ plane of the $\mathrm{y}$-axis scan. The scan speed is switch selectable; however, the NIJ standard uses a nominal speed of $1 \mathrm{~m} / \mathrm{s}$ for this performance test. The other inputs, "Delay" and "\# of SCANS," are not used for the speed test.

The front panel display for the speed test subVI for the HHMD is shown in fig. 7. The operator selects which measurement plane (see sec. 3.4.2.2) to perform the test. The y-axis scan passes through the detector axis (defined in ref. 1).

\subsubsection{Repeatability}

The repeatability test uses the same front panel as the speed test. The only difference with this test is that the "\# of SCANS" and "Delay" inputs are required. The NIJ standard calls for 50 repeats of this test. There is an indicator to the right of the portal cartoon that indicates the number of scans performed. The delay input is used to meet the maximum allowable delay requirement between 
subsequent trials stated in the NIJ standard. The indicators "SCANNING" and "DONE" are used to denote the status of the test. The "AT LOCATION" indicator is used to show the user when the robot positioner has arrived at the selected location in the $\mathrm{X}-\mathrm{z}$ plane.

\subsubsection{Discrimination}

The discrimination test uses the same front panel as the speed test. The only difference is that the user must randomly replace the selected test objects, one of the appropriate size class and the other an innocuous-item test object, on the end of the object holder.

\subsubsection{Throughput (WT only)}

The throughput test uses the same front panel as the speed test. The only difference is that the user must swap the selected test objects, one each of the appropriate size classes. Two test objects are used, one providing the largest detector response and one providing the smallest detector response as described in ref. 2. The test object providing the largest detector response is first run through at the appropriate location and then the test object providing the smallest detector response is run

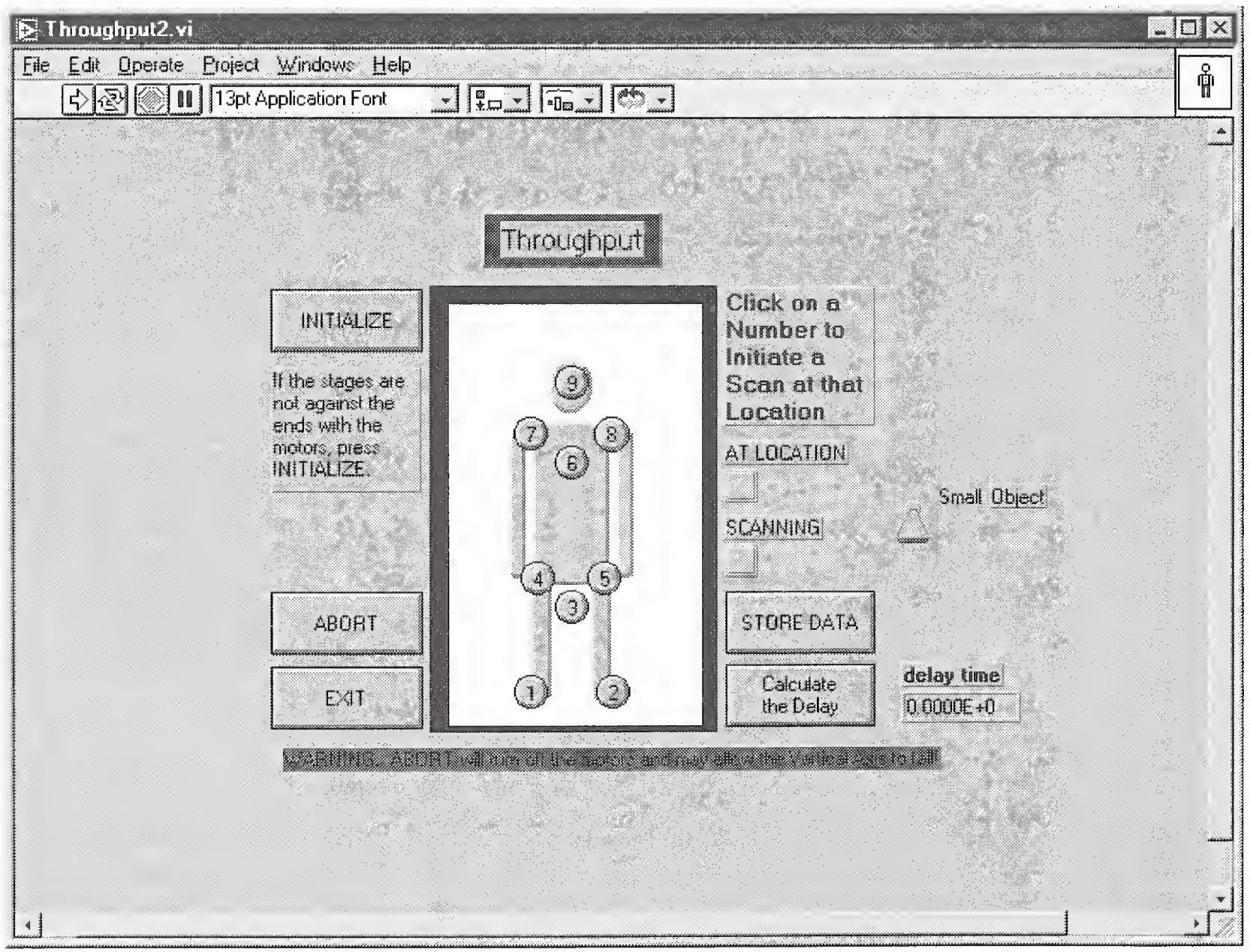

Figure 8. Front panel for the subVI used to perform the throughput test on the WTMD. 
through at its appropriate location. A time delay (in seconds) is calculated as described in sec. 3.8. The throughput, given in persons per minute, is computed by dividing $60 \mathrm{~s}$ by the time delay. 


\section{TEST METHODS}

\subsection{Conditions and Preparations}

The distance between any metal object other than a test object (see Section 3.2) and the closest part of the detector should be greater than 0.8 meter $(31 \mathrm{in})$ to avoid the possibility of any non-test object being sensed by the detector. The ambient temperature should be $21{ }^{\circ} \mathrm{C} \pm 2{ }^{\circ} \mathrm{C}$ and the relative humidity should be between 10 percent and 80 percent. The narrow range of temperature and humidity is to ensure that the measurement instruments function properly. The operational temperature and humidity range for the HH and WT detectors are much wider than these ranges.

The walk-through metal detector is secured to a detector holder (see fig. 9) and otherwise installed according to the manufacturer's instructions. Any setup or calibration adjustments specified in the operator's manual should be performed if required. The handheld metal detector is placed in a holder as shown in fig. 10. Attach the detector to the robot using appropriate adapters (see sec. 2.7 of refs. 1 and 2). These adaptors maintain a fixed distance and $\mathrm{x}$ axis registration between the detector holder and the robot.

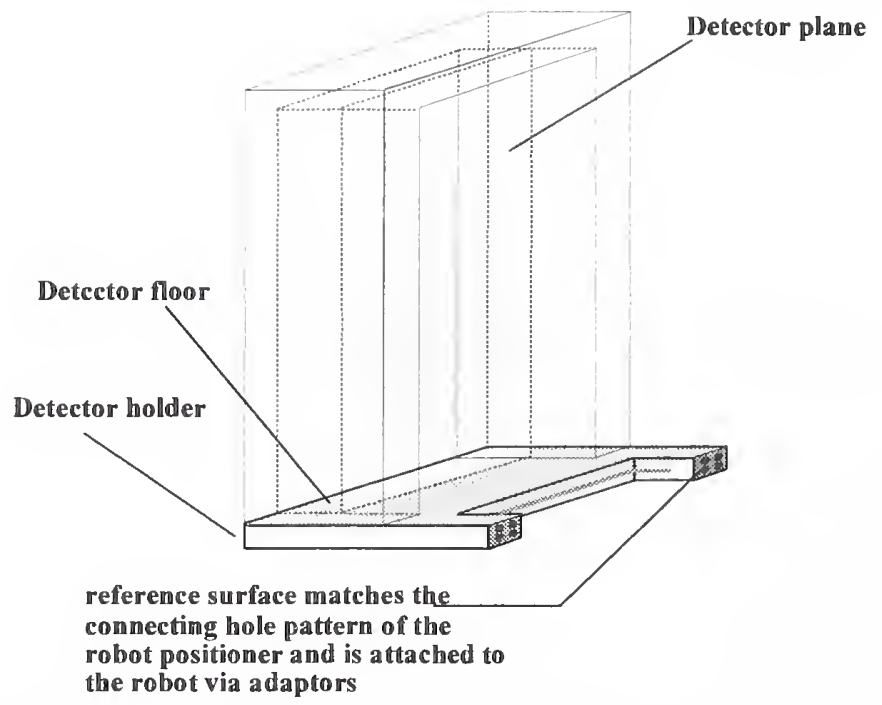

Figure 9. Diagram showing the detector and the detector mount.

Except for the magnetic field test, the measurements are relative and, therefore, instrument calibration is not essential. The other measurements are a pass/fail type and are based on the observation of an alarm from the detector. For the magnetic field test, the response function (voltage signal output as a function of magnetic field strength) of the magnetic field sensors must be measured using a calibration procedure or provided by the manufacturer.

Test the operation of each instrument before performing any measurements. Ensure that the robot will not hit any objects during motion. Some $\mathrm{HH}$ units use a momentary switch to power the detector instead of a toggle switch. In this case, the user should ensure the momentary switch is securely depressed so that the detector is powered during the tests. 


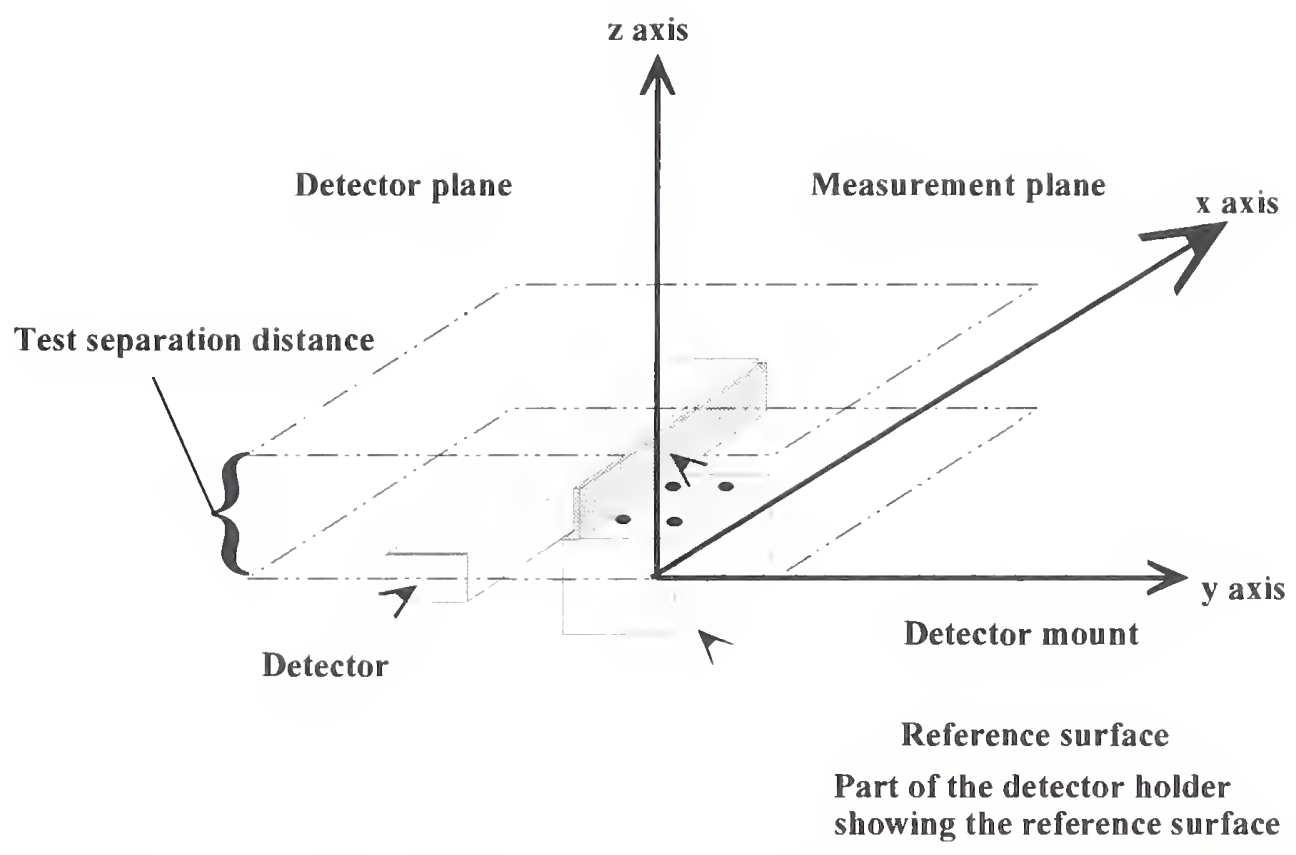

Figure 10. Diagram of a HH metal detector attached to the detector holder which is separated from the detector positioner. The separation between the detector plane and the measurement plane is the test separation distance.

\subsection{Test Objects}

The purpose of the test objects is to provide standards for performance measurements and a basis for measurement comparison. This allows all WT and HH units produced by manufacturers to be tested for compliance to the revised standard and objectively compared. The test objects are described in references 1 and 2 and are replicas of items that law enforcement and corrections agencies have defined as weapons or contraband. The test objects are classified based on size, and the size classifications are small, medium, and large. Large-sized test objects are replicas of small handguns and knives, medium-sized test objects are replicas of handcuff keys and \#2 Phillips screwdriver bits, and small-sized test objects are replicas of pen refills and disposable razor blades. The small-sized test objects are not used in the performance tests of the WT units. The test objects are encapsulated in a block of plastic to enhance safety and allow for orientation- dependent performance measurements. All plastic blocks are the same size and have orientation holes on three surfaces. The orientation holes allow a maximum of three block rotation angles: $0^{\circ}, 45^{\circ}$, and $90^{\circ}$.

\subsection{Initial Test Procedures, General}

Ensure that the oscilloscope and robot are connected to the computer controller and the detection signal output connector (see section 2.6 .3 of references 1 and 2) is connected to the voltmeter. Turn on the voltmeter, oscilloscope, computer controller, and robot and verify that all the instruments are 
operating. Ensure that the metal detector is securely located and positioned with respect to the robot. Ensure that the test object or magnetic field sensor does not hit any objects while in motion.

\subsection{Detection Sensitivity}

\subsubsection{General Description}

This method is used to assess the ability of the HH and WT metal detectors to detect the target objects. Since the detector may be qualified for different sizes of target objects, the detector's performance must be assessed for each appropriate target size. In this method, the test objects are passed through certain locations with respect to a reference coordinate of the detector. The orientation of the test object is also varied to assess the detection performance of the HH and WT metal detectors.

\subsubsection{Performing the Test}

Turn on the metal detector and verify that the metal detector is responding by moving a metal object by the detector and noting an alarm indication.

\subsubsection{Walk-through Metal Detector}

Set the position program to perform a series of $y$-axis scans in the $\mathrm{x}-\mathrm{z}$ plane as shown in fig. 11. A measurement of the detection sensitivity should be taken at $2 \mathrm{~cm} \pm 0.1 \mathrm{~cm}$ separations in both the $\mathrm{x}$ and $\mathrm{z}$ directions. To prevent the test objects from hitting the sides, top, or bottom of the WT metal detector during the test, the scan length for the $\mathrm{x}$ axis should be $5 \mathrm{~cm}$ less than the width of the portal and the scan length for the $\mathrm{z}$ axis should be $5 \mathrm{~cm}$ less than the height of the portal. Figure 11 graphically shows a possible scan procedure. The circles in fig. 11 depict the $\mathrm{x}$ - and $\mathrm{z}$-axis locations where a measurement should be taken. The numbered circles indicate possible first, second, and third measurement locations. The serpentine line indicates a possible series of locations that are used to measure the

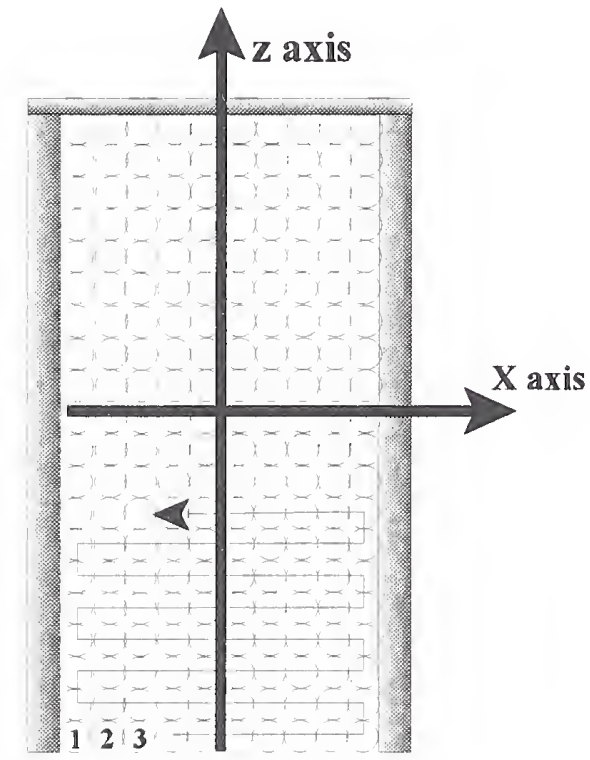
detection sensitivity throughout the portal of the WT metal detector.

\subsubsection{Hand-held Metal Detector}

Set the position program to perform an $x-y$ scan over the measurement plane at a test separation distance of $2.5 \mathrm{~cm} \pm 0.1 \mathrm{~cm}$ (unless otherwise indicated by the manufacturer as allowed in sec. 2.7 


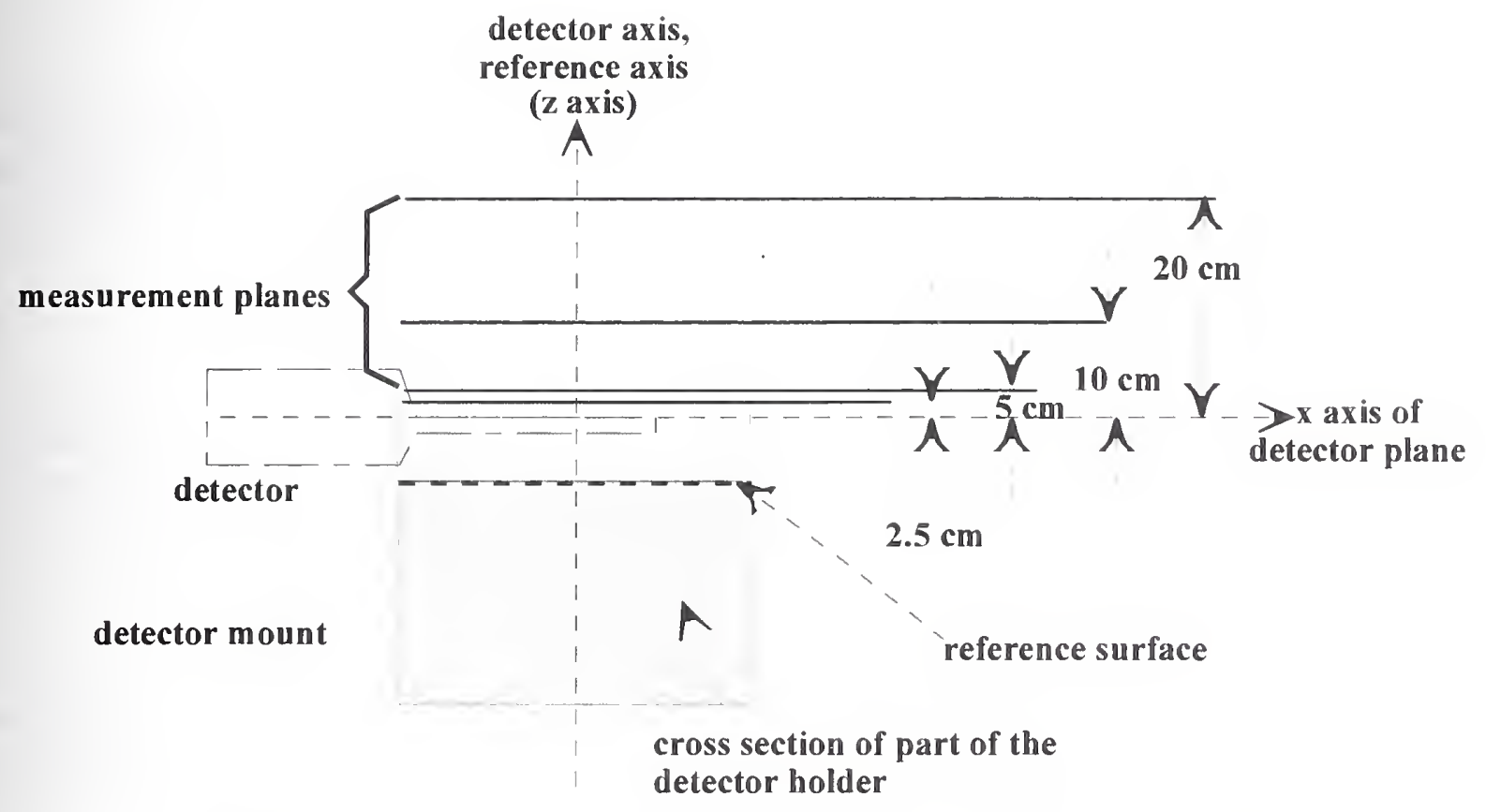

Figure 12. A cross section of the detector located within the detector mount and showing different measurement planes.

of ref.1) from the detector plane (see fig. 12). A measurement of the detection sensitivity should be taken at $1 \mathrm{~cm} \pm 0.1 \mathrm{~cm}$ separations in both the $\mathrm{x}$ and $\mathrm{y}$ directions. The $\mathrm{x}$ and $\mathrm{y}$ scans should each be $40 \mathrm{~cm} \pm 0.1 \mathrm{~cm}$ long. Repeat the detection sensitivity measurements for the measurement planes located at test separation distances of $5 \mathrm{~cm} \pm 0.1 \mathrm{~cm}, 10 \mathrm{~cm} \pm 0.1 \mathrm{~cm}$, and $20 \mathrm{~cm} \pm 0.1 \mathrm{~cm}$ (see fig. 12).

\subsection{Speed}

\subsubsection{General Description}

The purpose of the speed test is to determine how fast the $\mathrm{HH}$ metal detector can be moved past an object and still sense the object and how fast an object can pass through the portal of the WT metal detector and still be sensed by the detector. The speed ranges are from $0.05 \mathrm{~m} / \mathrm{s}$ to $2 \mathrm{~m} / \mathrm{s}$, basically from a "snail's" pace to a jog.

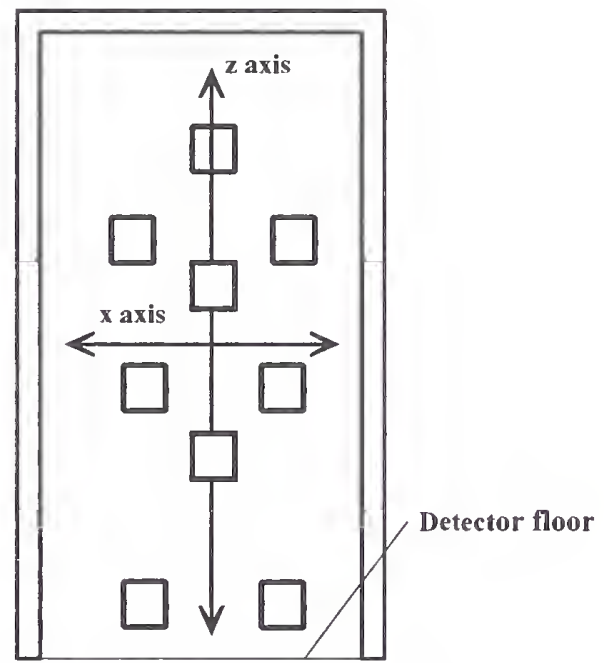

Figure 13. Diagram illustrating the nine test measurement locations (gray shaded areas). 


\subsubsection{Performing the Test}

Adjust the detector to the appropriate sensitivity setting. Attach the test object with the proper orientation to the robot. Turn on the metal detector and ensure that the detector output is functioning properly by noting a change in the oscilloscope display as a metal object is brought near the metal detector.

\subsubsection{Walk-through Metal Detector}

Set the computer program to perform a $1 \mathrm{~m}$ long $\mathrm{y}$-axis scan at the specified speed and specified $\mathrm{x}$ axis and z-axis positions (see fig. 13) such that the y-axis scan is perpendicular to, passes through, and is centered at the detector plane. Note any audible alarm.

\subsubsection{Hand-held Metal Detector}

Set the position program to perform ay-axis scan passing through the detector axis in the appropriate measurement plane at the specified speed. Note any audible alarm. The center of the y-axis scan should be the detector axis and the scan length should be $40 \mathrm{~cm} \pm 0.1 \mathrm{~cm}$.

\subsection{Repeatability}

The repeatability test uses the same procedure as the speed tests (see sec. 3.5) with the exception that the speed of the $y$-axis scan is fixed at $1 \mathrm{~m} / \mathrm{s}$.

\subsection{Discrimimatiom}

The discrimination test uses the same procedure as the speed tests (see sec. 3.5) with the exception that the speed of the y-axis scan is fixed at $1 \mathrm{~m} / \mathrm{s}$ and that two objects are used. The two objects represent a threat item and an innocuous item (as defined in refs. 1 and 2).

\subsection{Throughput (WT only)}

\subsubsection{General Description}

The throughput test is used to determine the ability of the WT metal detector to recover after exposure to an object that caused a large detection response. The method requires that a larger and then a smaller test object be passed through the portal of the WT metal detector and that the detection response signal for these objects be recorded as they pass through the portal. These two signals, one from the larger object and one from the smaller object, will be used to compute the throughput (explained in more detail in sec. 3.8.2). Recall, in sec. 3.2 it was stated that small-sized test objects are not used in the performance tests of WT units. Although the throughput of a WT unit may depend on the speed of an object passing through the portal, this test is performed at a speed of $1 \mathrm{~m} / \mathrm{s}$ only. 


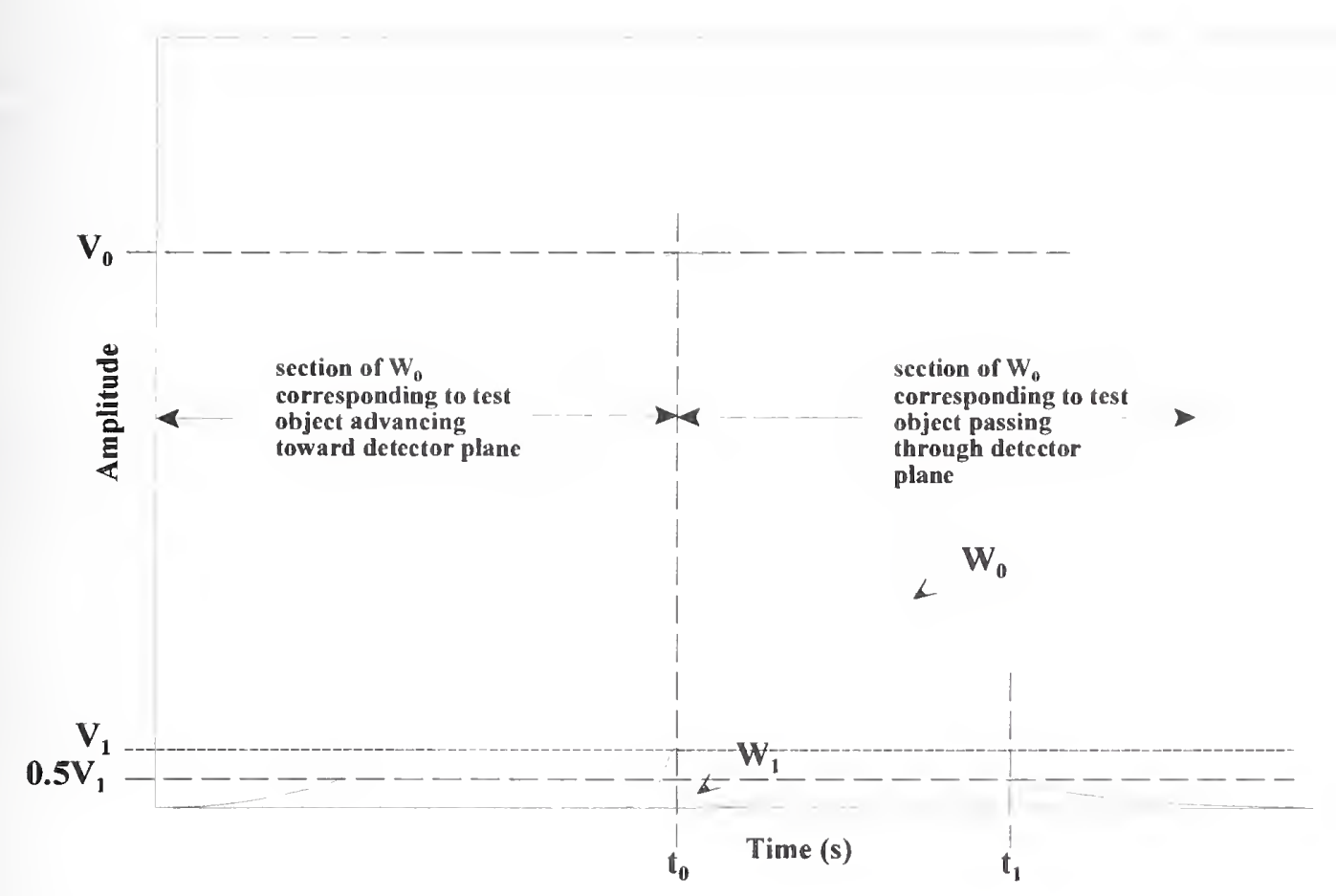

Figure 14. Diagram of possible detector response waveforms, one from a large object (labeled $W_{0}$ ) and the other from a small object (labeled $W_{1}$ ).

\subsubsection{Performing the Test}

Adjust the detector to the appropriate sensitivity setting. Attach a large-sized test object to the robot. Turn on the WT metal detector and ensure that the detector output is functioning properly by noting a change in the oscilloscope display as a metal object is brought near the portal region of the WT metal detector. Set the computer program to perform a $1 \mathrm{~m}$ long y-axis scan at a speed of $1 \mathrm{~m} / \mathrm{s} \pm$ $0.01 \mathrm{~m} / \mathrm{s}$ passing through each of the test measurement locations. Record the response waveform for each large-sized target size test object for each possible orientation of the test object. Store the waveform having the largest amplitude response from this set of tests for the large-sized test objects and label this waveform as $W_{0}$ (see fig. 14). Record the peak amplitude of $W_{0}$ as $V_{0}$ and its time of occurrence on $W_{0}$ as $t_{0}$. Perform a similar set of scans for each medium-sized test object. Record the response waveform for each medium-sized test object for each possible orientation of the test object. Store the waveform having the smallest amplitude response from this set of tests for the mediumsized test objects and label this waveform as $W_{1}$. Record the peak amplitude of $W_{1}$ as $V_{1}$. Locate the time of occurrence of $0.5 \mathrm{~V}_{1}$ on $\mathrm{W}_{0}$ and label this time as $\mathrm{t}_{1}$. Subtract $\mathrm{t}_{0}$ from $\mathrm{t}_{1}$ and divide 60 by this difference to obtain the throughput in people per minute. 


\subsection{Magnetic Field Test}

\subsubsection{General Description}

The magnetic field test is used to acquire the waveform that represents the time-varying magnetic field produced by the metal detector. The waveform is recorded by an oscilloscope and the internal firmware of the oscilloscope is used to compute the peak-to-peak amplitude and average power of the detector's magnetic field.

\subsubsection{Performing the Test}

Ensure that the response of the magnetic field sensor has been calibrated. Set the oscilloscope parameters so that at least one full period of the detector's time-varying magnetic field can be observed. The following are suggestions for initial settings:

a) Vertical gain: least sensitive

b) Trigger: if an external synchronization or trigger is provided by the detector, connect this trigger to the trigger input of the oscilloscope and set the oscilloscope to external trigger. If an external trigger is not available, set the oscilloscope to trigger on the input signal.

c) Record epoch: sufficient to see the required region of waveform

d) Delay: appropriate to see the required region of the waveform

e) Number of waveform data pairs: $\geq 1024$

f) Internal averages: $\geq 256$

Securely position and orient the magnetic field sensor in the detector plane to provide the largest observable deflection on the oscilloscope. Readjust the vertical gain so that the maximum vertical deflection is observed on the oscilloscope. Direct the oscilloscope to acquire the waveform. After the oscilloscope has finished acquiring the waveform, use the internal firmware to calculate the peakto-peak amplitude and average power of the magnetic field. If internal firmware is not available, read the waveform into the computer controller, and use the computer software to calculate the peak-topeak amplitude and average power of the magnetic field. 


\section{REFERENCES}

1. N. G. Paulter, Hand-held Metal Detectors for Use in Concealed Weapon and Contraband Detection, NIJ-STD-0602.01, National Institute of Justice, U.S. Government Printing Office, Washington, DC, March, 2000.

2. N.G. Paulter, Walk-throngh Metal Detectors for Use in Concealed Weapon and Contraband Detection, NIJ-STD-0601.01, National Institute of Justice, U.S. Government Printing Office, Washington, DC, March, 2000. 


\subsection{Appendix 1, Parts list for robotic positioner and hand-held detector holder.}

\begin{tabular}{|c|c|c|c|}
\hline Description & Quantity & Part No. & Manufacturer/Supplier \\
\hline \multicolumn{4}{|l|}{ BASE ASSEMBLY } \\
\hline X-Axis Platform & 1 & NIST $X-3$ & \\
\hline X-Axis Mounting Base & 2 & NIST $X-1$ & \\
\hline Actuator Horizontal Base & 1 & NIST $X-4-1$ & \\
\hline Actuator Horizontal Base & 1 & NIST $X-4-2$ & \\
\hline X-Axis Position Detector Support & 1 & NIST $X-5$ & \\
\hline Mounting Foot & 6 & JFF-19306 & Reid Tool \\
\hline Linear Glide & 2 & 1DBJ00-S x 66" & Thomson Industries \\
\hline Ball Screw Assembly & 1 & BSA16T x 54" & Thomson Industries \\
\hline Motor Assembly & 1 & $\mathrm{BLX341B2E000}$ & Thomson Industries \\
\hline Socket Head Screw \#3/8-16 x 1.5" Long & 11 & & \\
\hline Socket Head Screw \#1/4-20 x 1" Long & 16 & & \\
\hline Socket Head Screw \#1/4-20 × 1.5" Long & 8 & & \\
\hline Socket Head Screw \#10-32 x .75" Long & 4 & & \\
\hline \multicolumn{4}{|l|}{ VERTICAL ASSEMBLY } \\
\hline Actuator Vertical Brace & 2 & NIST Z-3 & \\
\hline Z- Axis Mounting Plate & 1 & NIST Z-1 & \\
\hline Actuator Mounting Plate & 2 & NIST Z-2 & \\
\hline Z-Axis Cross Support & 1 & NIST Z-4 & \\
\hline Linear Guide & 1 & 2RA-M160CM-L230 & Thomson Industries \\
\hline Linear Guide & 1 & 2REM160EMBX $\times 2300 M M$ & Thomson Industries \\
\hline Motor & 1 & $\mathrm{BLX} 234 \mathrm{~A} 2 \mathrm{E} 000$ & Thomson Industries \\
\hline Gear Head & 1 & 16831B-3015 & Thomson Industries \\
\hline Brake & 1 & TEB23F & Thomson Industries \\
\hline Brake Controller & 1 & TBC-7 & Thomson Industries \\
\hline T-Slot Nut & 4 & NIST Z-5 & \\
\hline T-Slot Nut Retainer & 4 & NIST Z-6 & \\
\hline Socket Head Screw M5 x 50 MM & 16 & & \\
\hline Socket Head Screw M5 x 15 MM & 8 & & \\
\hline Socket Head Screw \#3/8-16 × 2" Long & 10 & & \\
\hline Socket Head Screw \#3/8-16 x 1.5" Long & 4 & & \\
\hline \multicolumn{4}{|l|}{ Y ASSEMBLY } \\
\hline Linear Guide & 1 & 2REM160EMBS $\times 1700 \mathrm{MM}$ & Thomson Industries \\
\hline
\end{tabular}




\begin{tabular}{|c|c|c|c|}
\hline Motor & 1 & BLX234A2E000 & Thomson Industries \\
\hline Gear Head & 1 & $34-614662-6975$ & Thomson Industries \\
\hline Sample Holder & 1 & NIST Y-1 & \\
\hline Sample Holding Rod & 1 & NIST Y-2 & \\
\hline Square Rod Holder & 2 & NIST Y-3 & \\
\hline T Nut & 4 & M6 & Thomson Industries \\
\hline Socket Head Screw M6 x $70 \mathrm{MM}$ & 4 & & \\
\hline Nylon Screw & 1 & 090832125TEG & Micro Plastics Inc. \\
\hline Nylon Screw & 4 & 090832050TEG & Micro Plastics Inc. \\
\hline \multicolumn{4}{|l|}{ Controllers } \\
\hline Cabinet & 1 & $10225-318$ & Cal-Greg Components \\
\hline Fused Switch with Neon Lamp & 1 & PS1, PS1-BZ, 009-18250 & Heinemann-Eaton \\
\hline Power Line Filter & 1 & FN350-30-33 & Schaffner, Inc \\
\hline Controller Mounting Bar & 2 & NIST M-2 & \\
\hline \multicolumn{4}{|l|}{ Multi-Plug Strip } \\
\hline Central Controller & 1 & TMC-2004CO & Thomson Industries \\
\hline X Contoller & 1 & OD-010 & Thomson Industries \\
\hline Y Contoller & 1 & OD-010 & Thomson Industries \\
\hline Z Contoller & 1 & OD-010i & Thomson Industries \\
\hline Contoller Cable Pairs & 3 & 21209B-15 & Thomson Industries \\
\hline 9 Pin RS-232 Cable & 1 & & \\
\hline 37 Pin D-sub Minature Cable to BNC & 1 & (To trigger oscilloscope) & \\
\hline \multicolumn{4}{|l|}{ Hand-held Device Sample Holder } \\
\hline Hand-held Detector, Top Plate & 1 & NIST HH-1 & \\
\hline Hand-held Detector, Base & 1 & NIST HH-2 & \\
\hline Hand-held Detector, Side Plate & 2 & NIST HH-3 & \\
\hline Hand-held Detector, Brace & 1 & NIST HH-4 & \\
\hline Hand-held Detector, Legs & 4 & NIST HH-5 & \\
\hline \multicolumn{4}{|l|}{ Hex Head Bolt Nylon } \\
\hline$\# 1 / 4-20 \times 1.5 "$ Long & 24 & HBN-1420-24 & Small Parts, Inc \\
\hline \multicolumn{4}{|l|}{ Miscellaneous } \\
\hline Positioner & 1 & NIST M-1 & \\
\hline \multicolumn{4}{|l|}{ Hex Head Bolt Nylon } \\
\hline \#3/8-16 x 1.5" Long & 12 & $\mathrm{HBN}-3816-24$ & Small Parts, Inc \\
\hline
\end{tabular}




\subsection{Appendix 2, Robot positioner drawings}

The assembly and mechanical drawings for the robot positioner are given in this section. The first figure is the complete assembly and is followed by the mechanical drawings for the $y$-axis components. The base (which provides $\mathrm{x}$-axis motion) assembly figure and mechanical drawings follow the $y$-axis component drawings. The z-axis (vertical) assembly figure and mechanical drawings comprise the last set of drawings in this Appendix.

Assembly drawing of the robot positioner. 


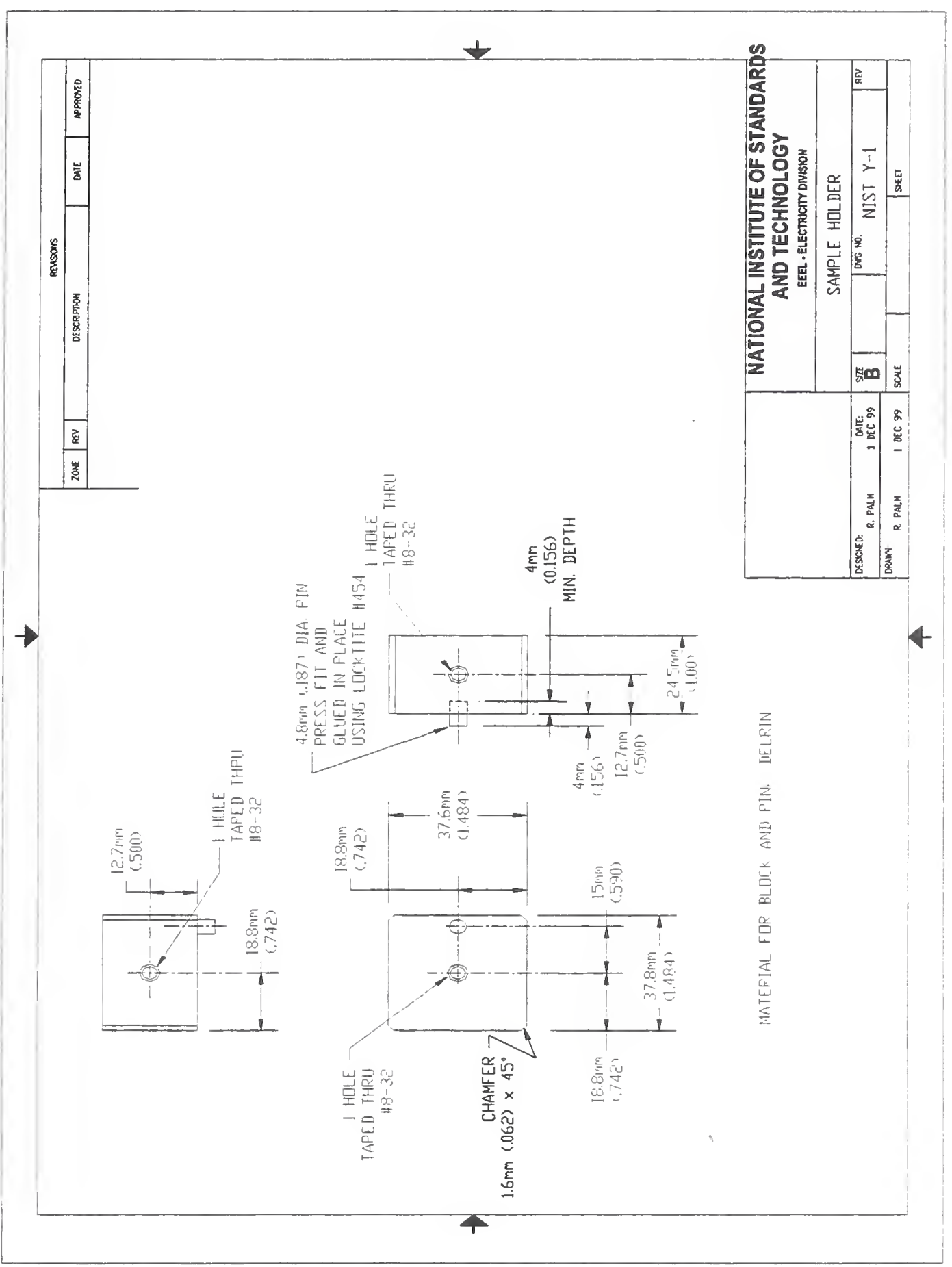




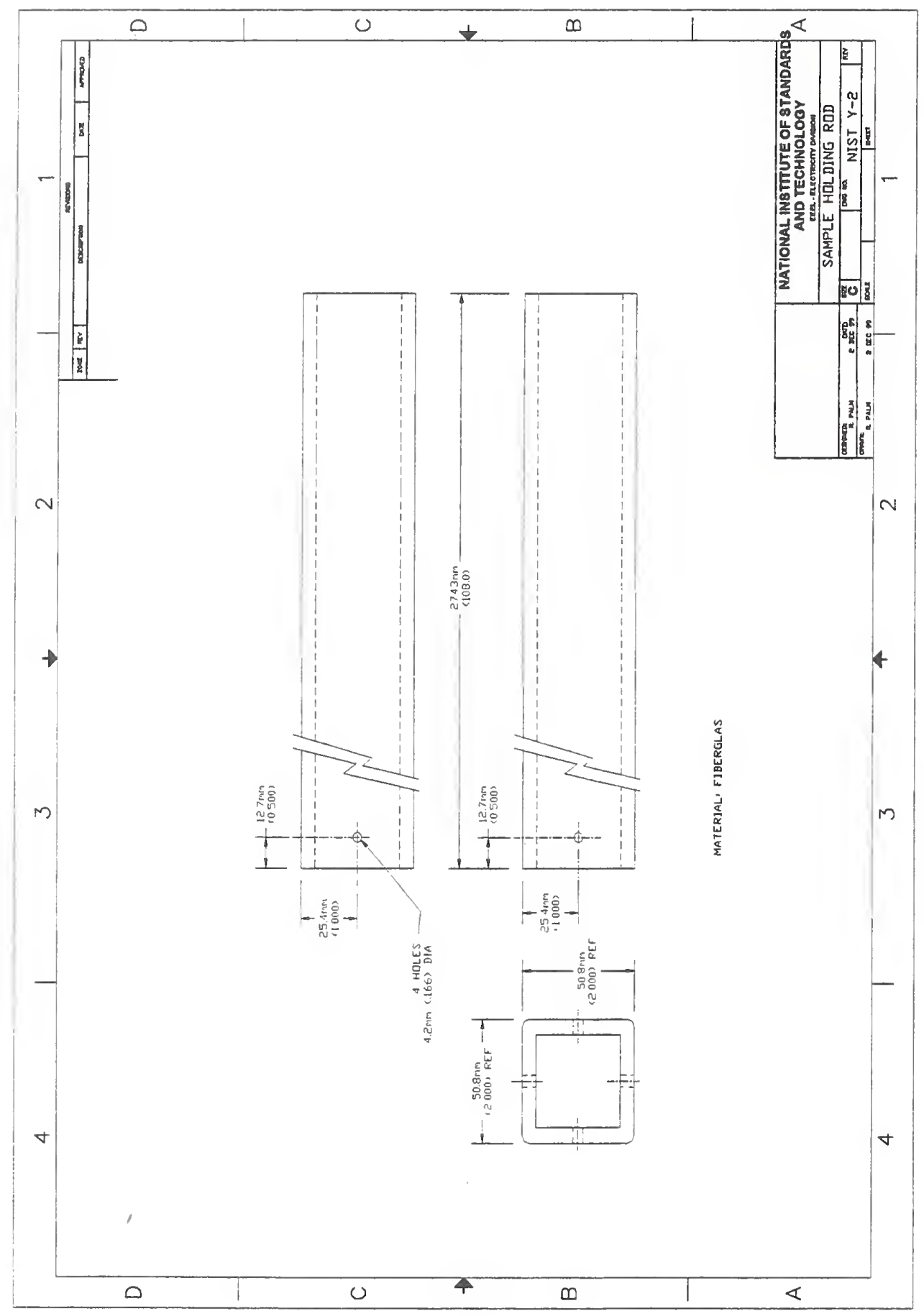




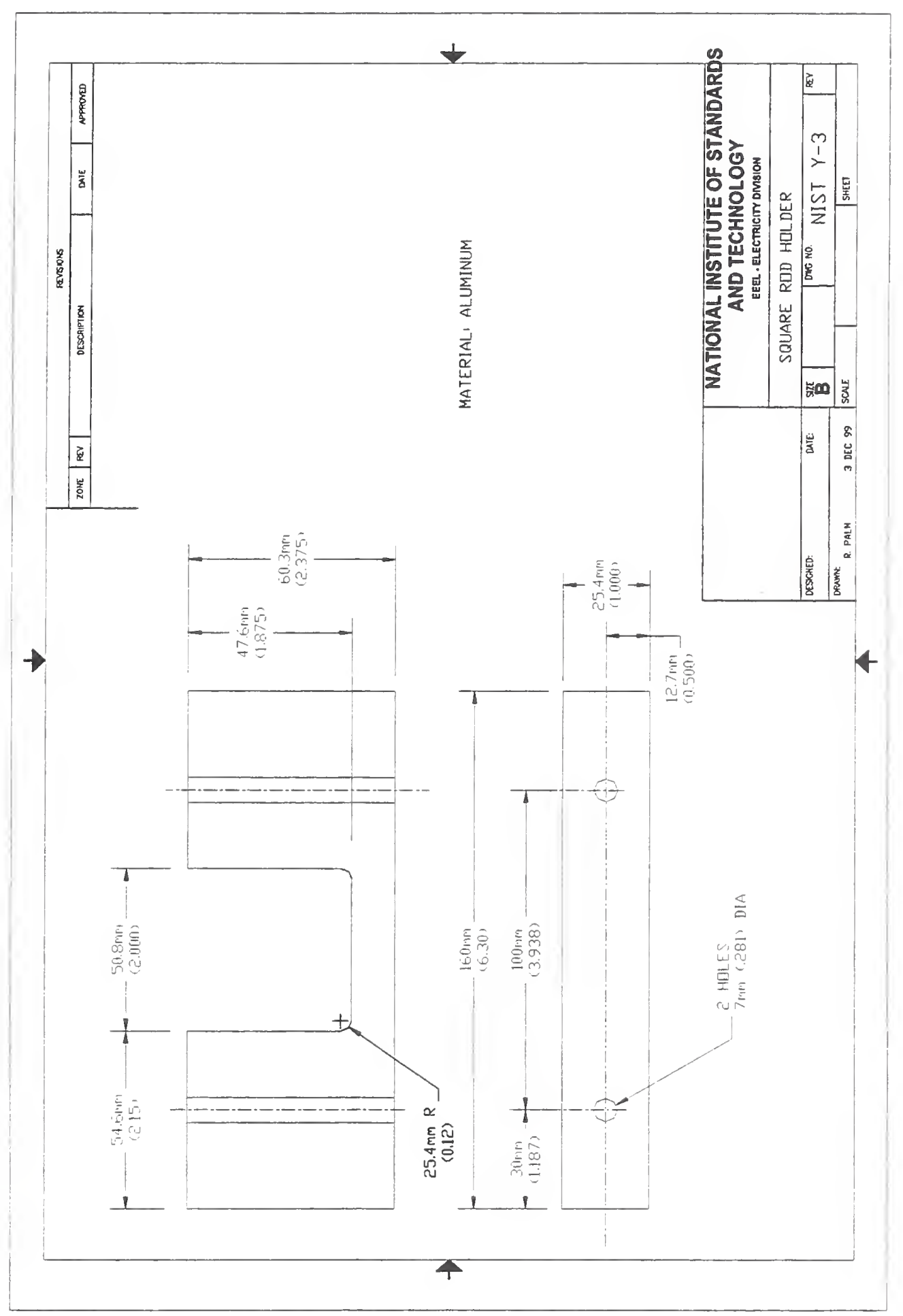




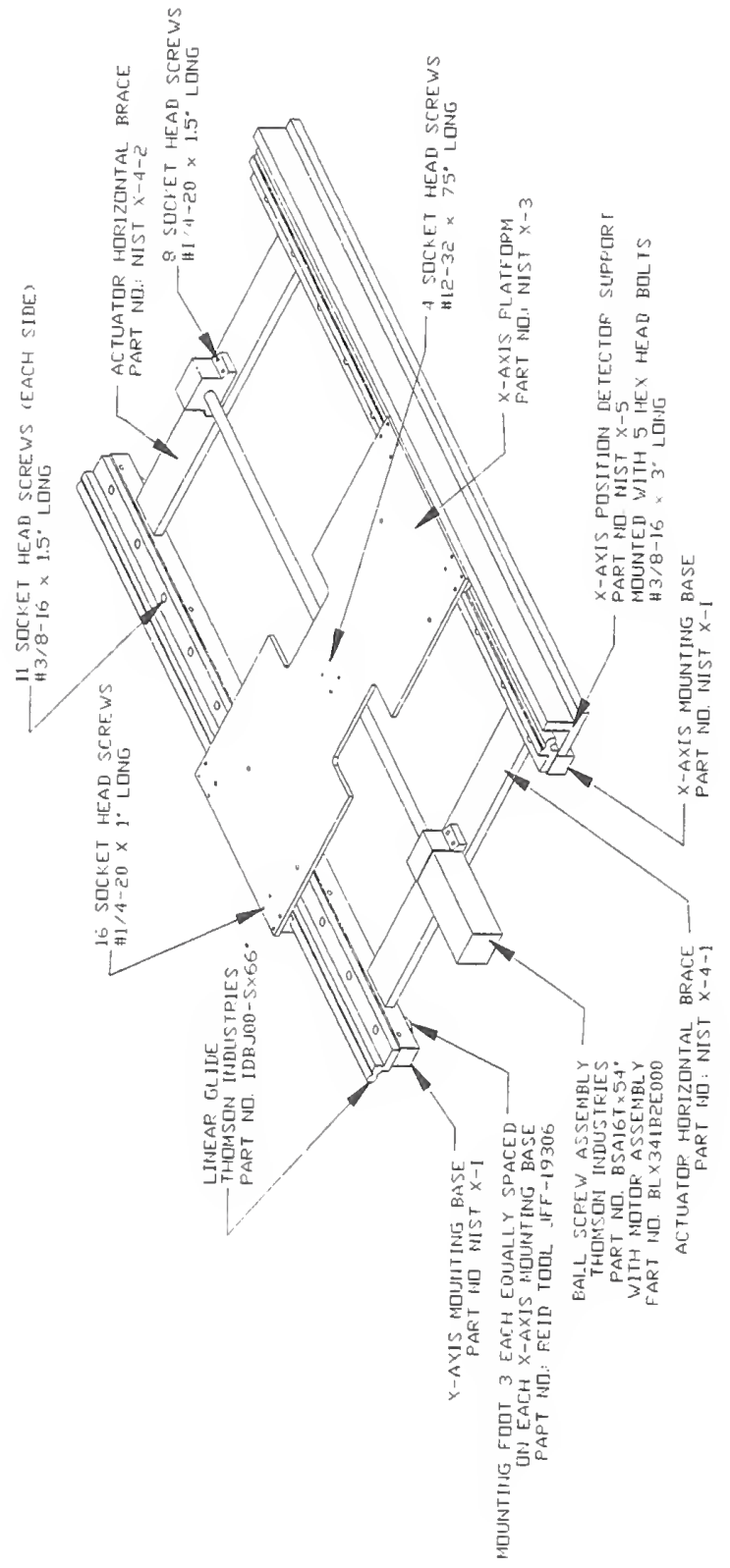

Drawing of the $\mathrm{x}$-axis assembly. 


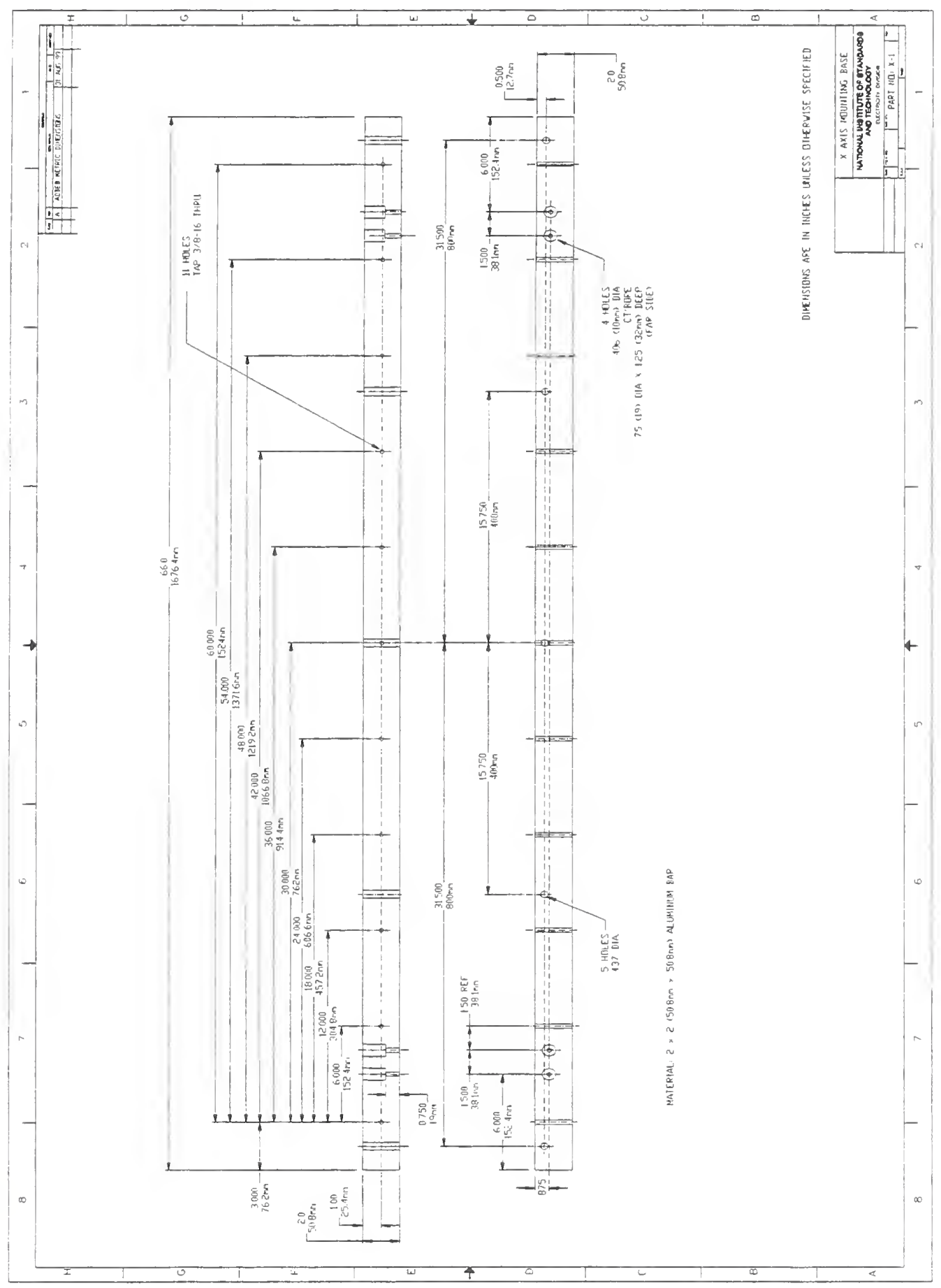




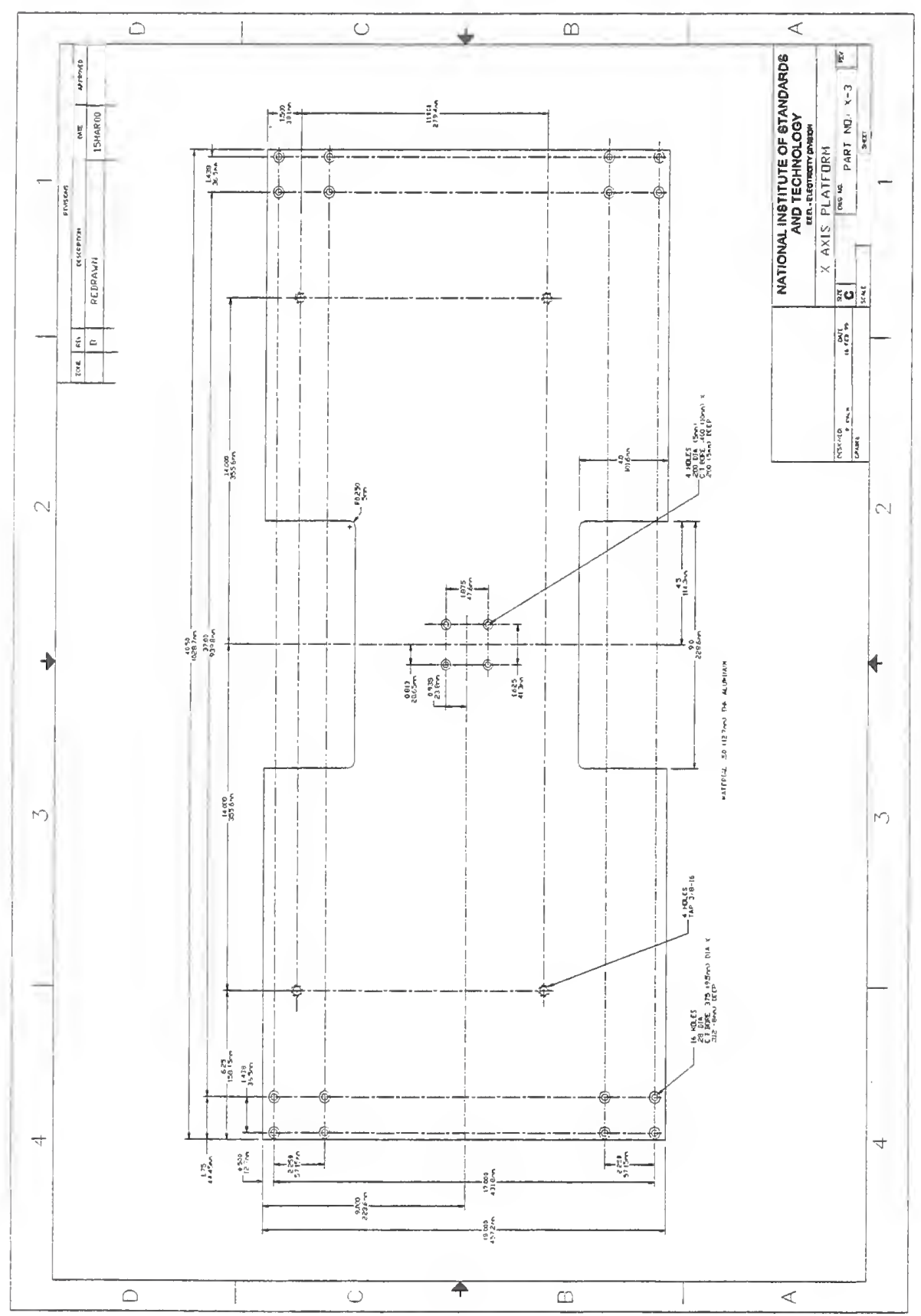




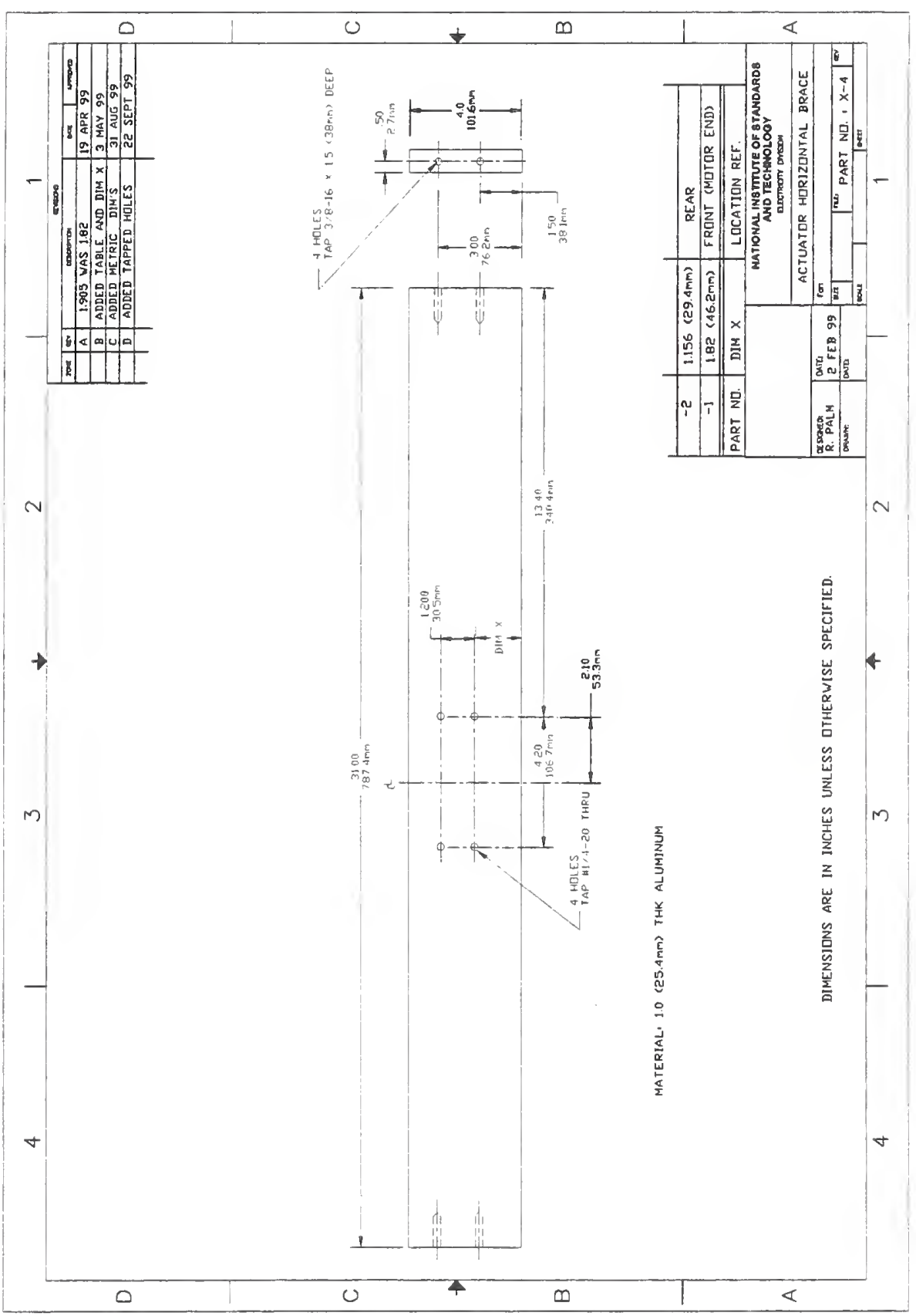




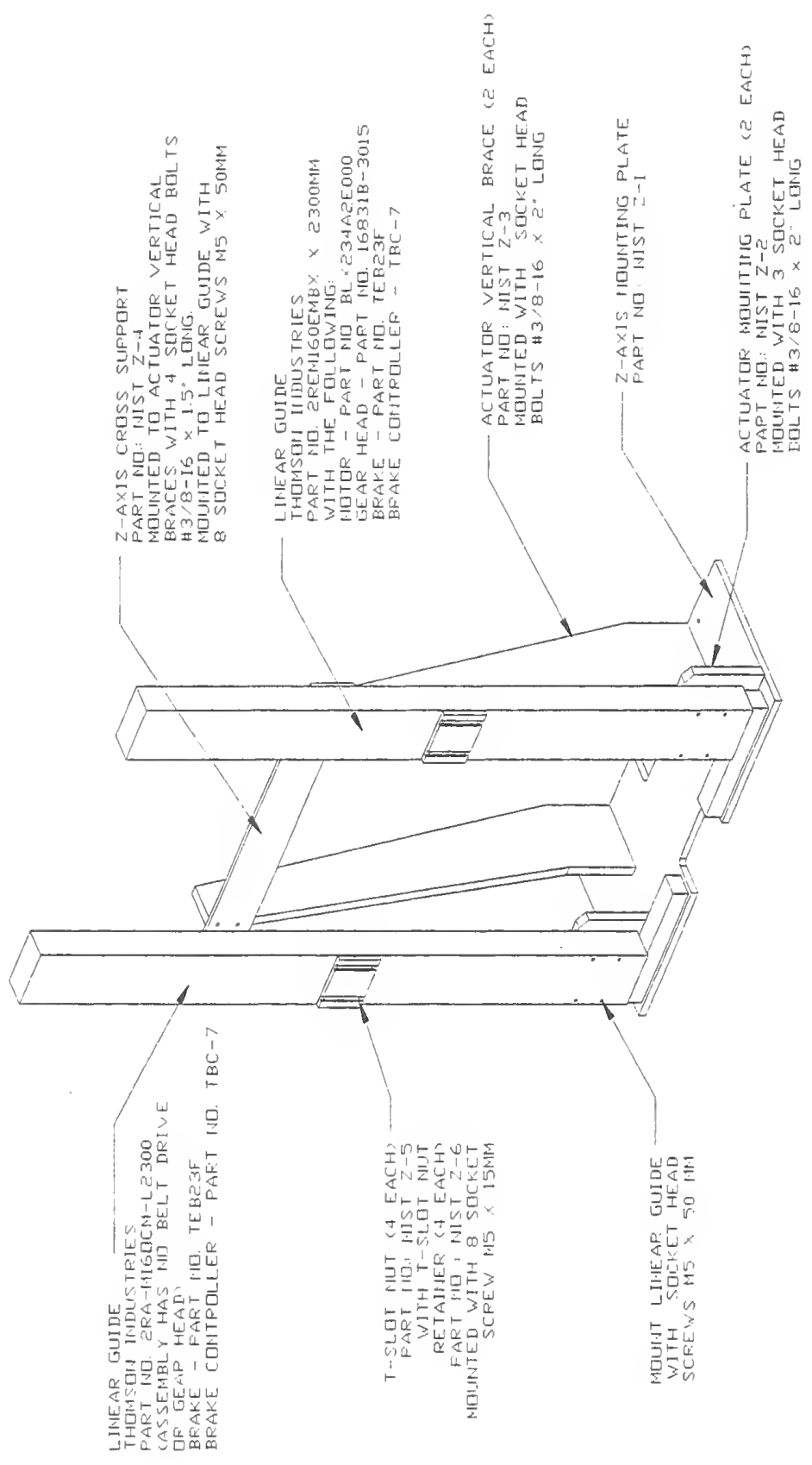

Drawing of the z-axis assembly. 


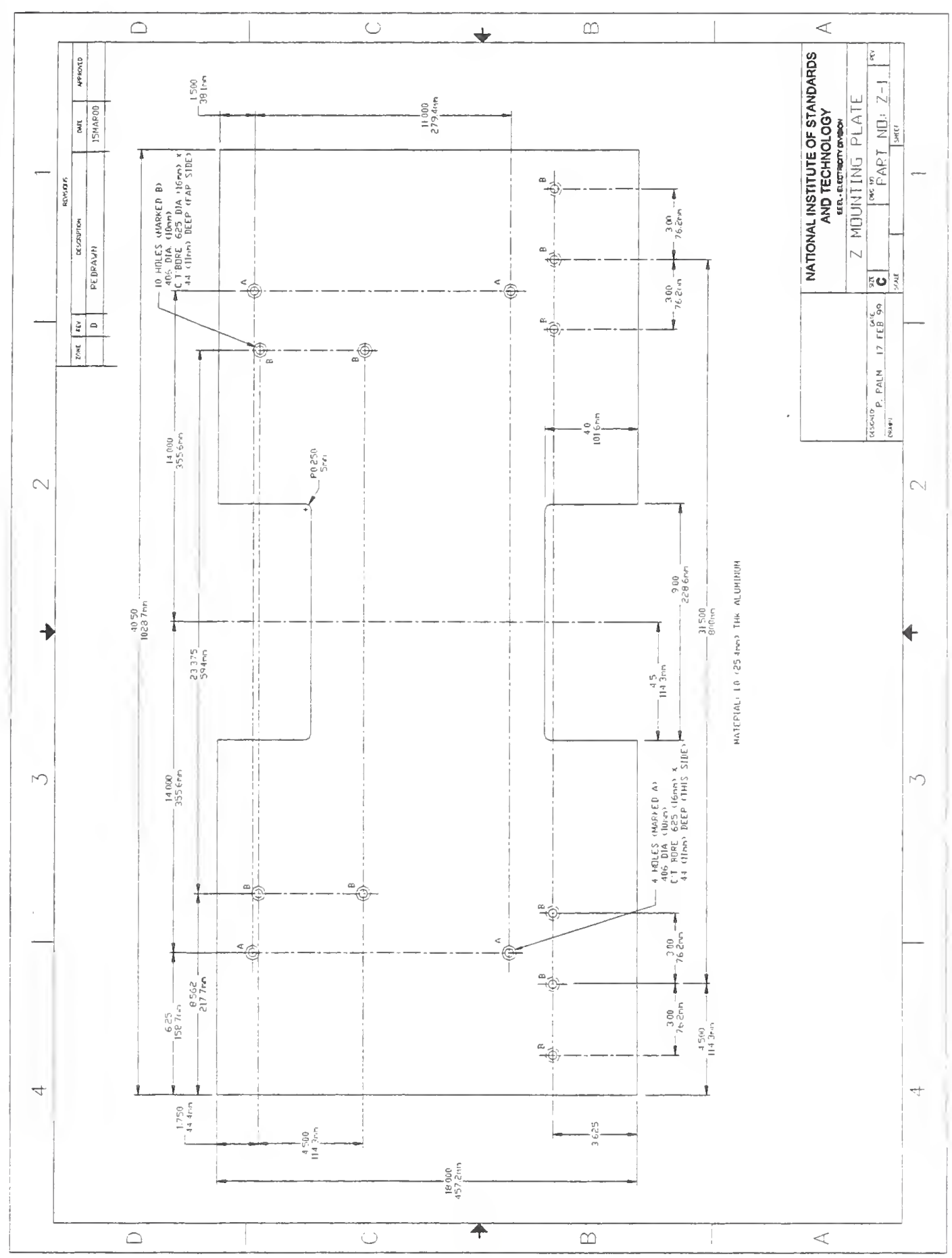




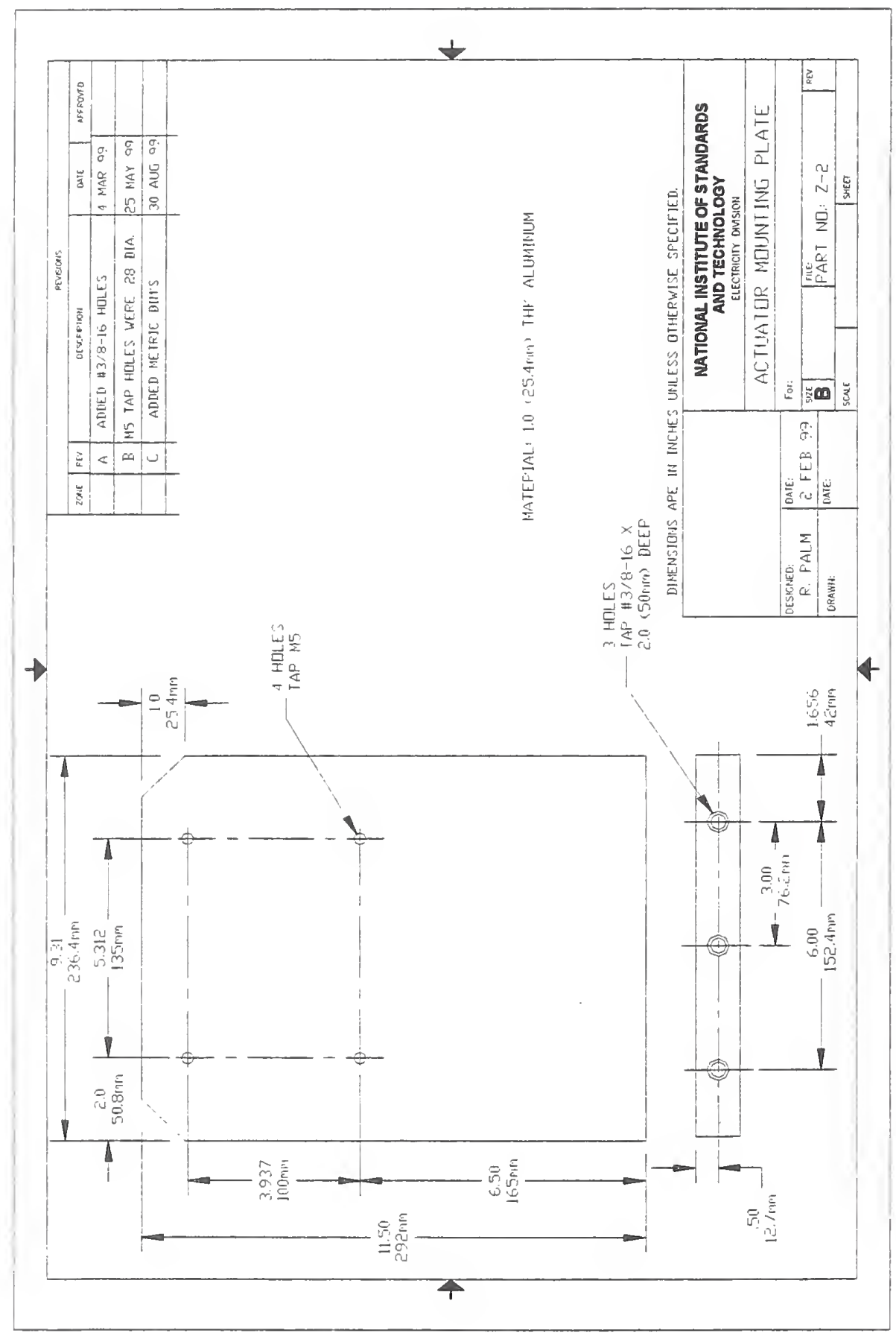




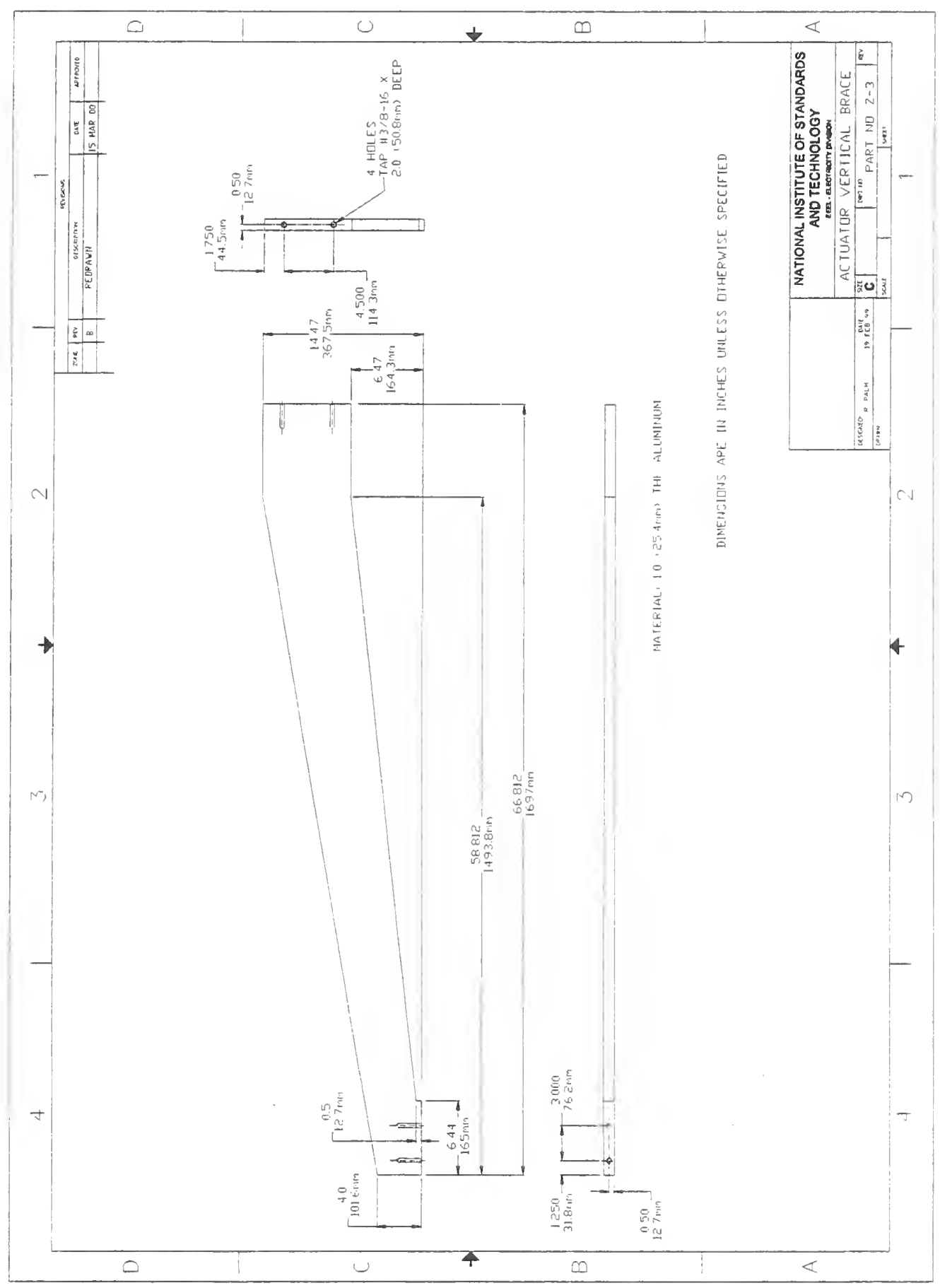




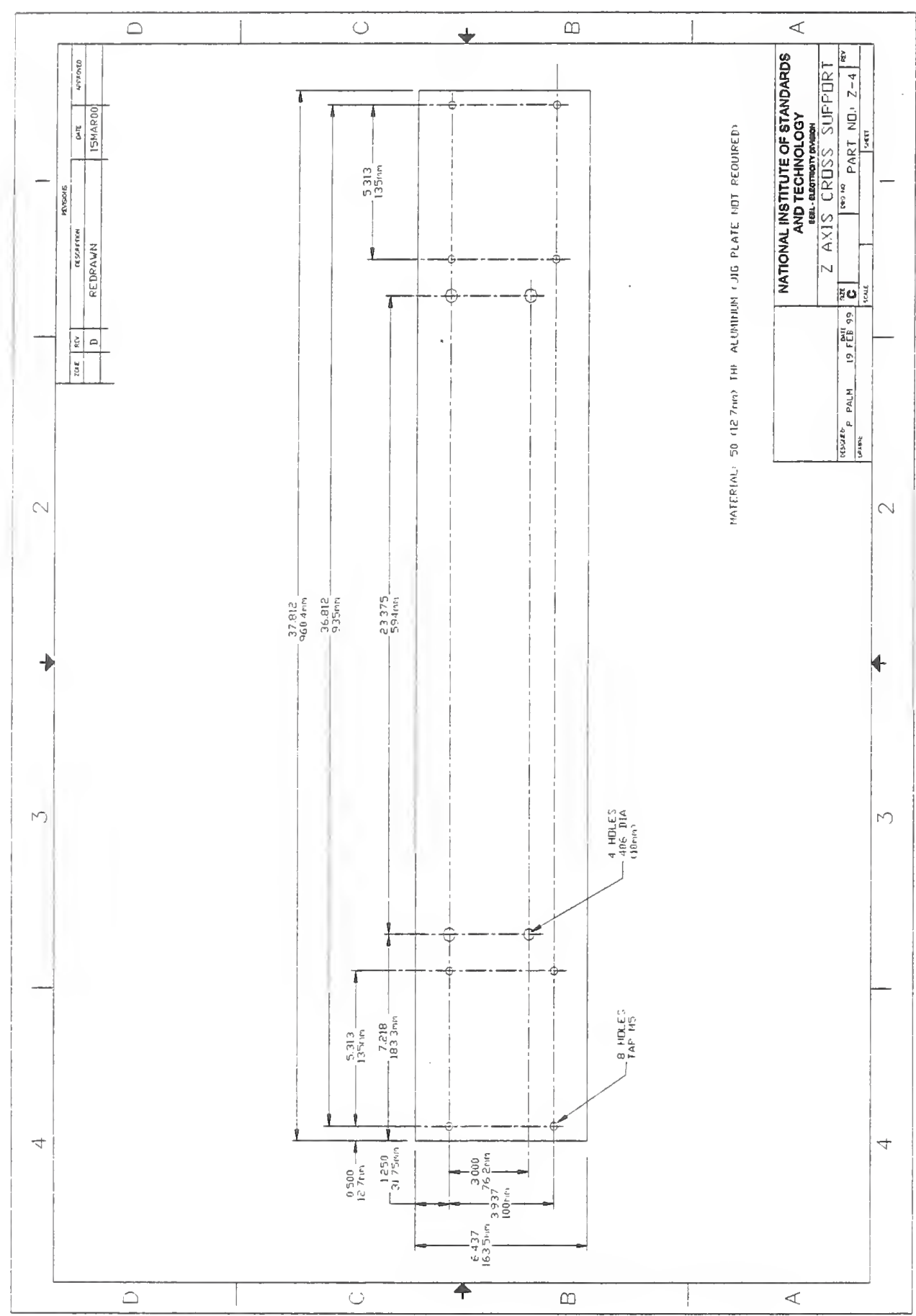




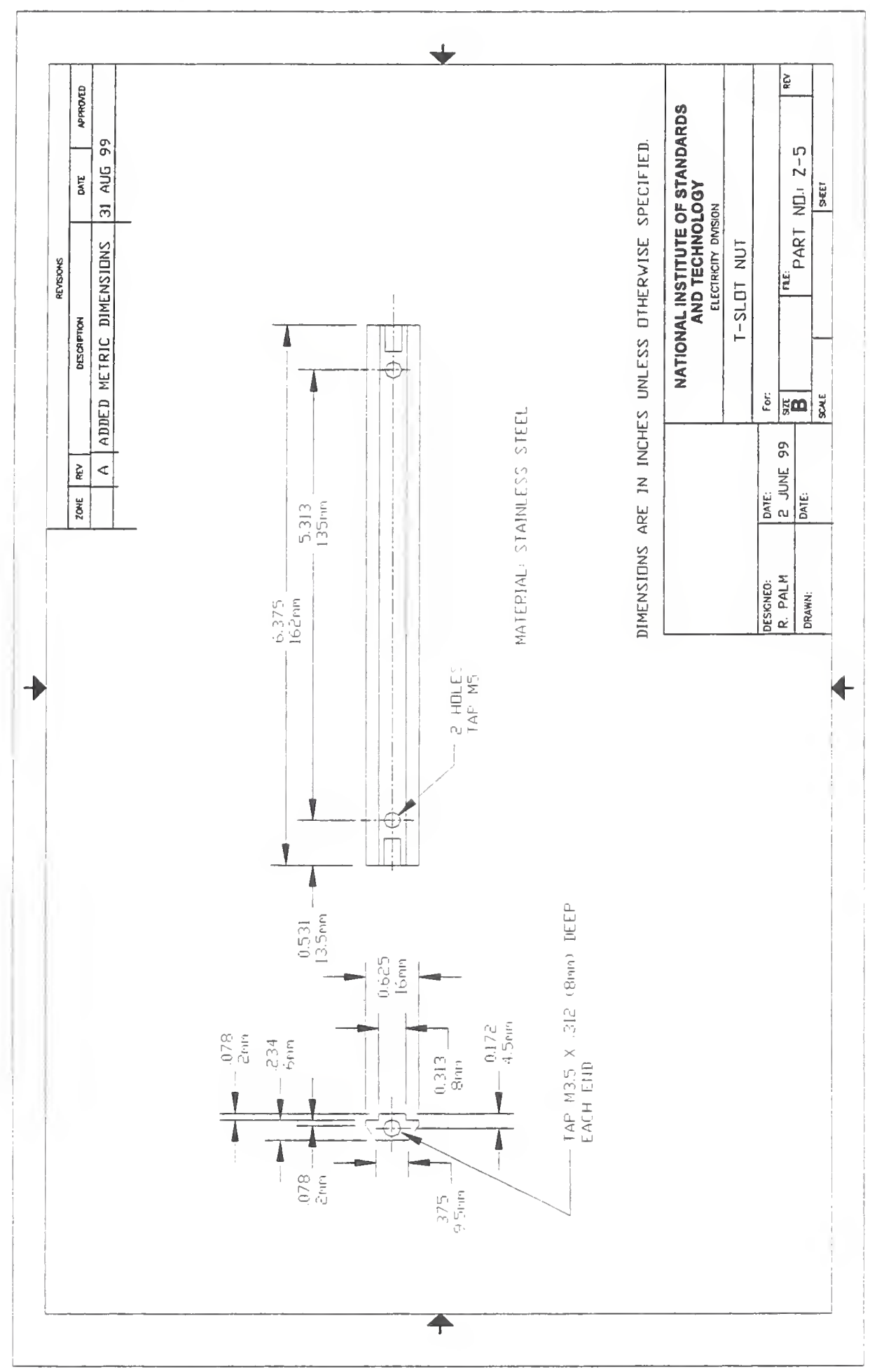




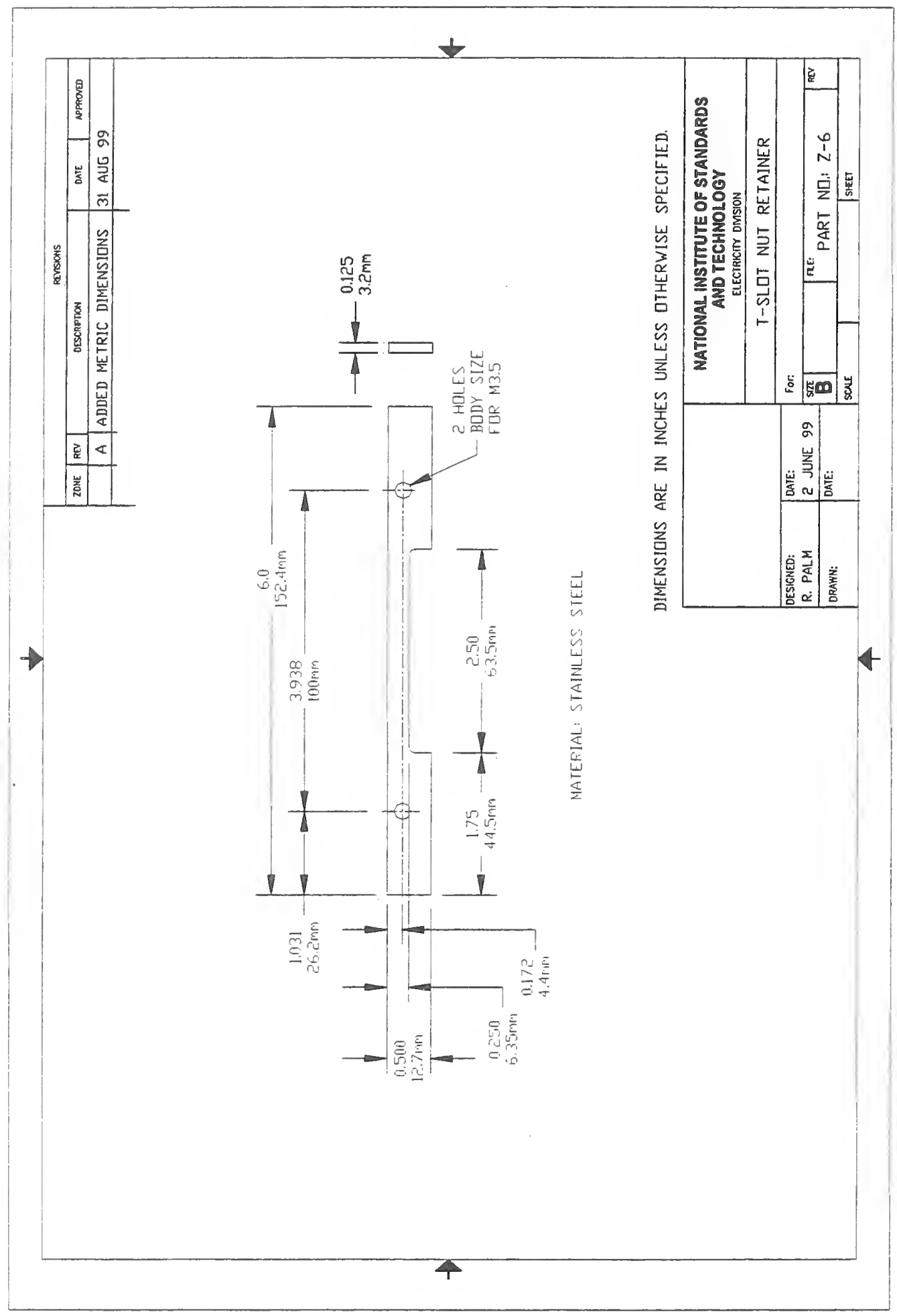




\subsection{Appendix 3, Hand-held metal detector positioner drawings}

The assembly and mechanical drawings for the holder that positions $\mathrm{HH}$ metal detectors with respect to the robot are given in this section. The first figure is the $\mathrm{HH}$ metal detector holder assembly drawing and the subsequent figures are the mechanical drawings.

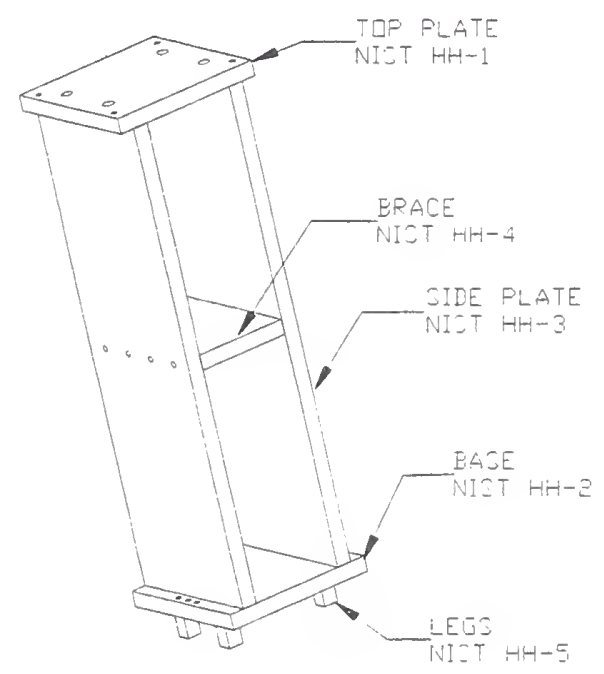

Sketch of the hand-held metal detector holder. 


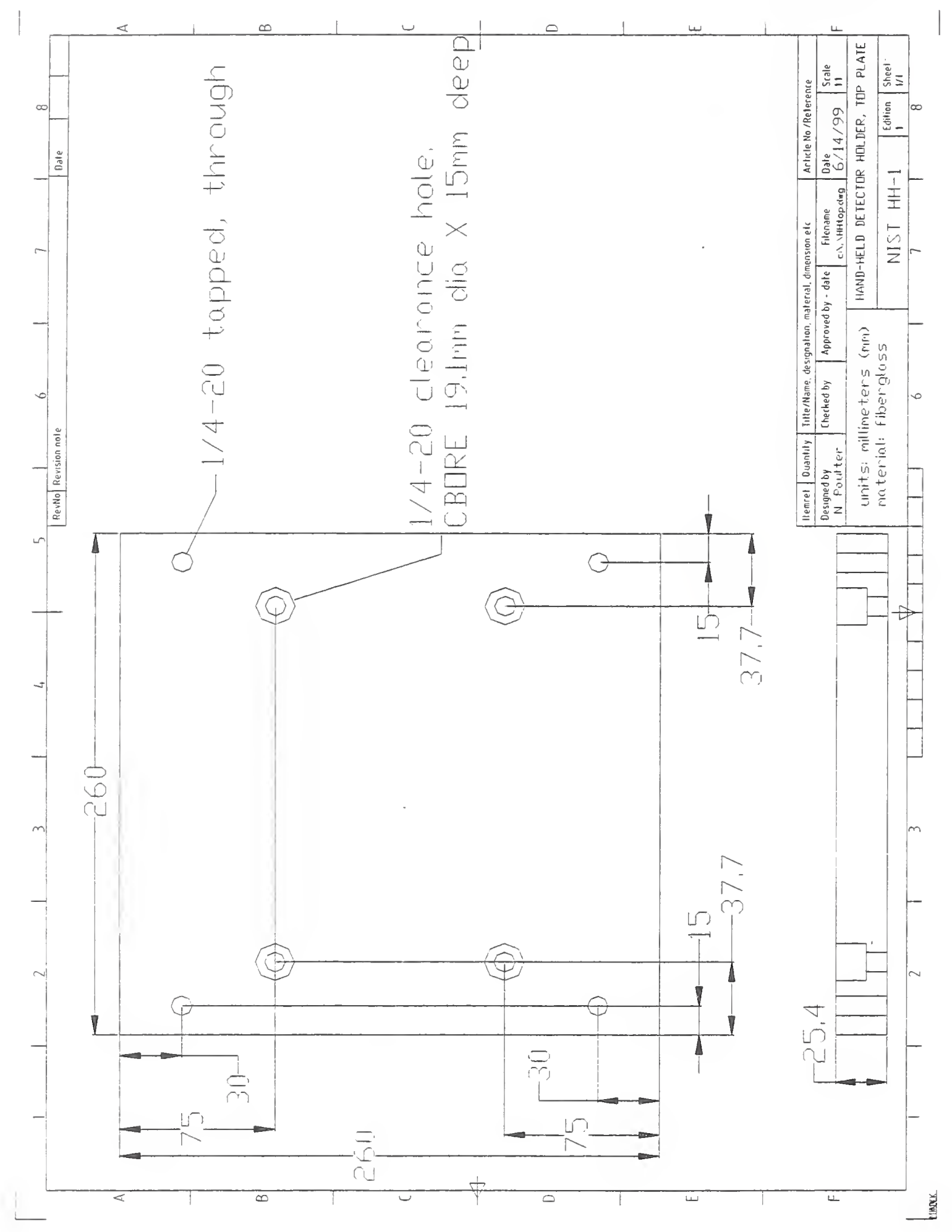




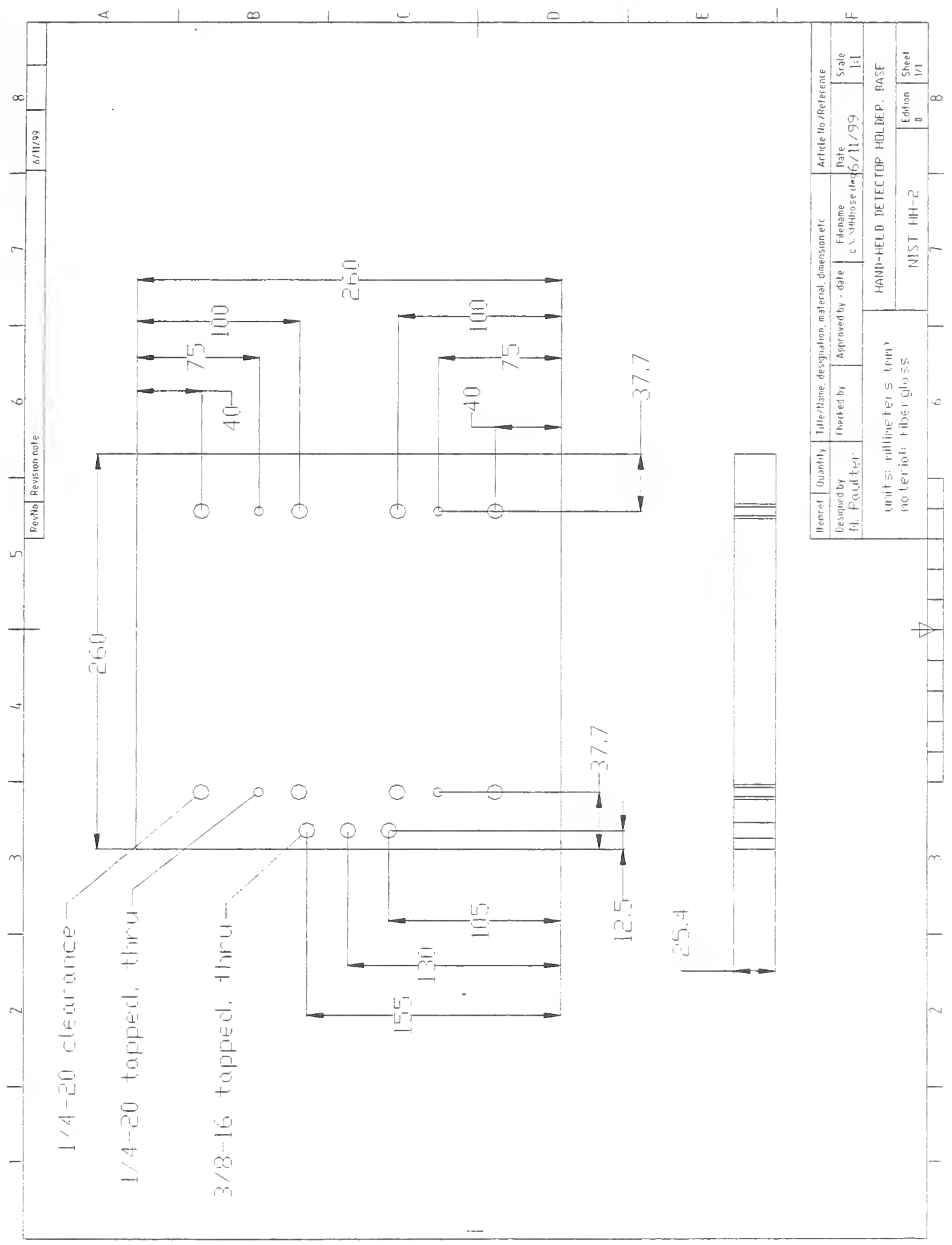




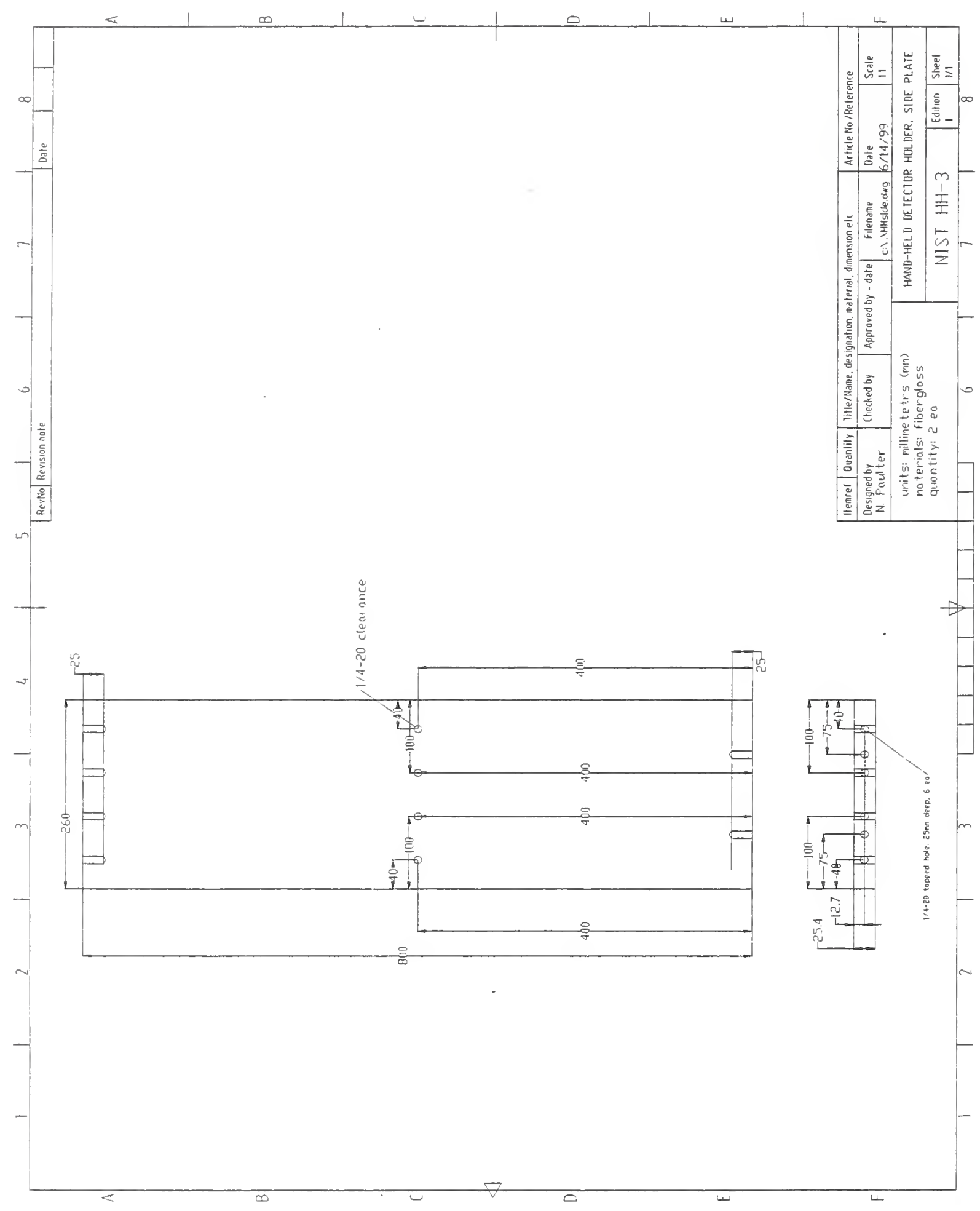




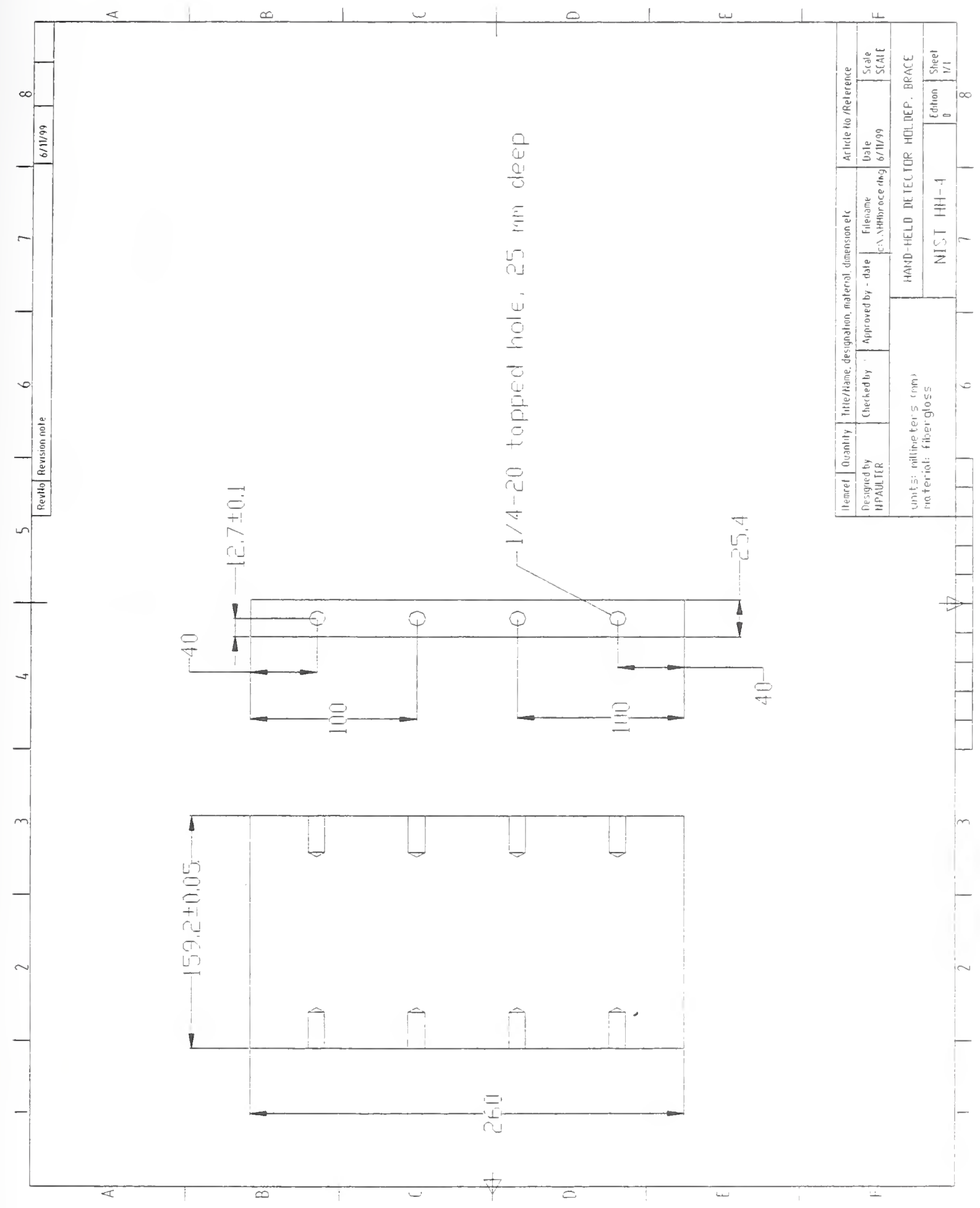




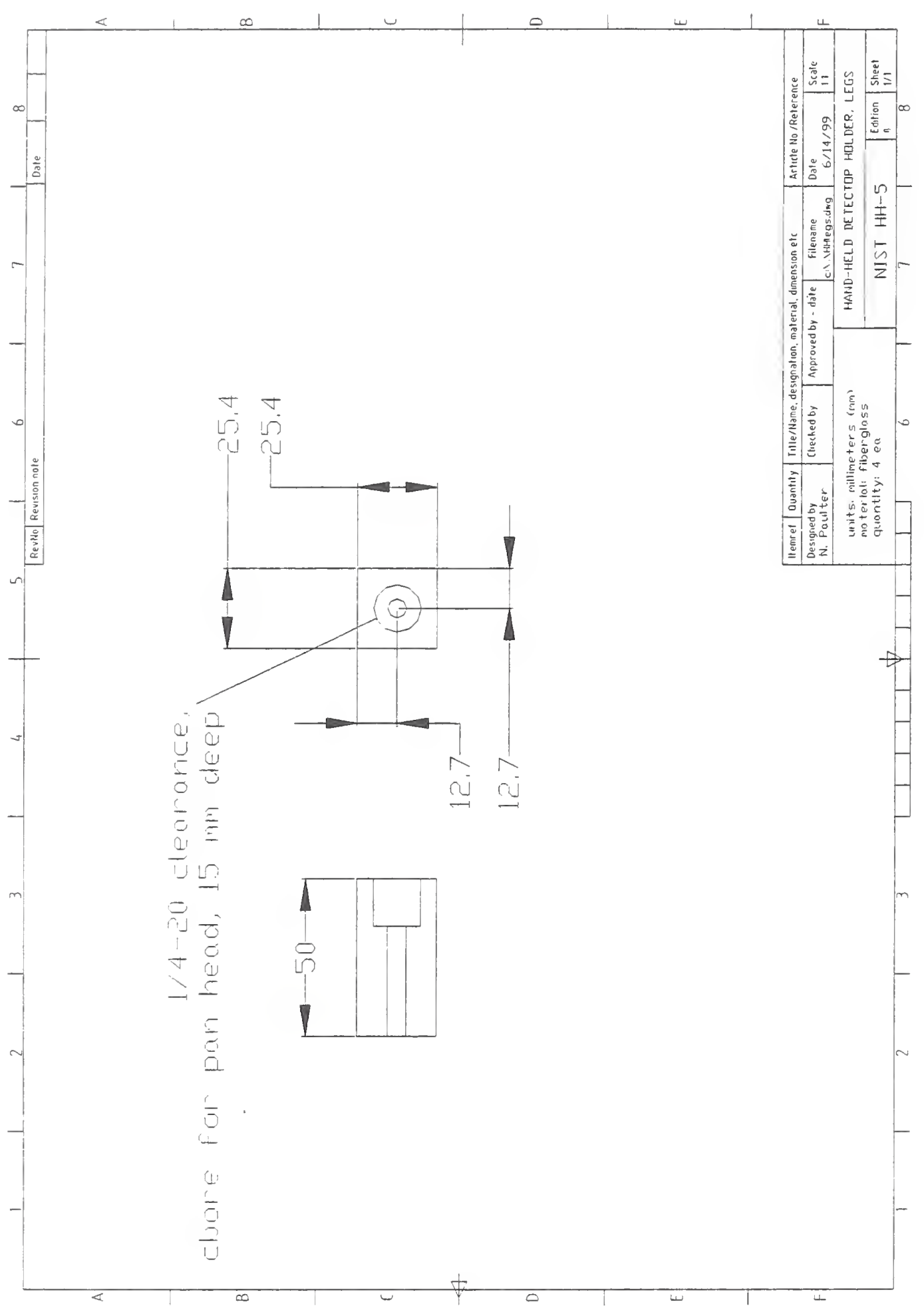


5.4 Appendix 4, Detector-holder-to-robot spacer drawing

This appendix contains the mechanical drawing of the bar that is used to maintain the proper separation between the detector holder (for either the hand-held or walk-through metal detectors) and the robot positioner. The length of part NIST M-1 is shown as nominal for a length of approximately $2.74 \mathrm{~m}$ for part NIST Y-2. The actual length part NIST M-1 will depend on the length of part NIST Y-2 and the discretion of the user. 


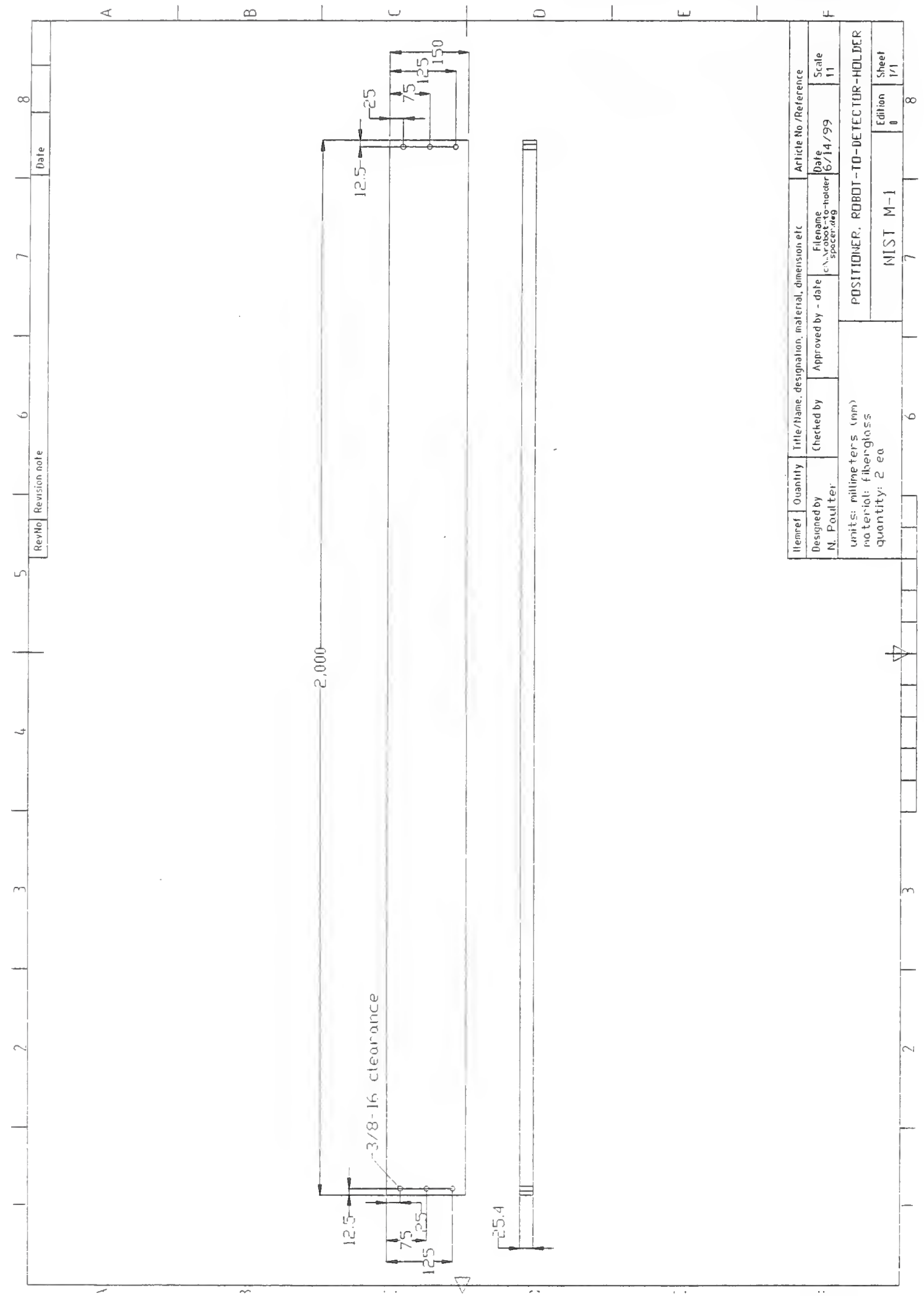





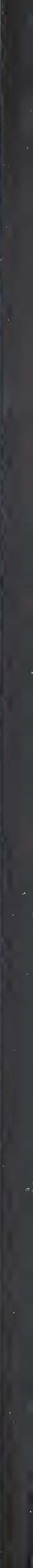

